\title{
Broca's Area (BA) and Language Articulation: Evidence from Arab Broca's Aphasic
}

\author{
Sadeq Ali Saad Al Yaari (Corresponding author) \\ Independent Researcher, Dept. of English, College of Arts, King Saud University (KSU) \\ Riyadh, Kingdom of Saudi Arabia. E-mail: prof.sadeq@gmail.com
}

Fayza Saleh Al Hammadi

Associate prof., Dept. of English, College of Arts, King Faisal University, Al-Hassa

Kingdom of Saudi Arabia. E-mail: viceii.library@kfu.edu.sa

\section{Salah Ayied Alyami}

Assistant professor, Dept. of English, Dammam University, Riyadh, Kingdom of Saudi Arabia. E-mail: salah1sa@yahoo.com

\begin{abstract}
Nassr Almaflehi
A professor of Statistics, College of Applied Medical Sciences, King Saud University (KSU) Riyadh, Kingdom of Saudi Arabia. E-mail: nassr_almaflehi@hotmail.com
\end{abstract}

Fahmi Mohammed Al-Senani

Consultant Neurologist, Neuroscience Center Deputy Director, Neurology Department Chairman, and Stroke Program Director-King Fahd Medical City (KFMC)

Received: January 1, 2013 Accepted: January 10, 2013 Published: January 17, 2013 doi:10.5296/ijele.v1i2.3064 URL: http://dx.doi.org/10.5296/ijele.v1i2.3064

\section{Abstract}

Background: Neurolinguists investigated the role of BA in language production in terms of what phonological or syntactic aspects are impaired. 


\section{Macrothink}

Aims: The purpose of this study is to investigate the role played by Broca's Area (BA) in articulating Arabic syllables, nouns, verbs, and sentences by studying Saudi patient with that developed Broca's aphasia as a result of suffering from a stroke.

Methods: After collecting data, one of the researchers interviewed the case at hand 5 times for 20 months (a session per 4 months). In each visit, the case was asked to repeat 84 Arabic syllables, 20 nouns, 20 verbs, and 20 sentences. The purpose of these sessions is to investigate whether or not Arabic phonological and syntactic aspects are affected in comparison to other languages. A test on production and selection of lexical items and another test on picture naming and selection were administered to the case. The researchers then transcoded the case's speech by transliterating it using the transliteration system (Romanization) recommended by American Library Association- Library of Congress (ALA-LC). The last step was to analyze speech linguistically before it was statistically analyzed.

Conclusions: Results of the present study show that both phonological and syntactic aspects of Arab Broca's aphasics are impaired. Also, Arab Broca's aphasics become unable to produce, name or select words and/ or pictures. Outlined findings have been discussed and analyzed with regard to the previous research and studies conducted on the same topic.

Keywords: Broca's Area, Arabic, Broca's aphasic, case study, stroke, language articulation, aphasia 


\section{Introduction}

The word "aphasia" is Greek-derived, with " $a$ " meaning "no", and "phasis" meaning "speech" (al-Faramāwī, 2009, P.109). In 1798, the word attained a technical meaning, so it denoted such silence that arose from doubt (Rockey, 1980). In the dictionary, aphasia is defined as loss in the power to use words, or of the faculty of speech, or of the ability to formulate language in the brain (Webster, 1981; Hedge, 1980a, 2001a, 2001b; Longman, 1995). The science of this phenomenon is called "Aphasiology" and has been investigated by many neurolinguists (Nielson, 1962; Geschwind, 1965a, 1965b).

There are several types of aphasia that lead to language impairments. People who lose the ability to repeat words have what is known as Conduction aphasia (Carlson \& Donald, 2007). This type of aphasia is most often caused by damage in the arcuate fasciculus (linker between Broca's area and Wernicke's area). Broca's aphasia (also called expressive/ non-fluent aphasia) is recognized by effortful speech which is full of stops (Agrammatism) as a result of the loss of small words (function words); it is usually called (telegraphic style). At the linguistic level, one way of studying Broca's aphasics' phonological and syntactic aspects is to focus on their performance in syllables, nouns, verbs, and sentences.

By comparison, Wernick's aphasia (also called receptive/ fluent aphasia) differs from Broca's aphasia. Unlike Broca's aphasia where comprehension is spread and production is impaired, here the former is impaired (damaged) while the latter is spread (intact) (Kolb \& Whishaw, 2003). In that sense, it can be said that language here is fluent, but the patient's speech is meaningless which means that he/ she has serious comprehension difficulties. For example, instead of using simple words to indicate something, he/ she may use a very long sentence.

Aphasia can also be totaling (global) and this is the most serious type of aphasia. Global aphasia is defined as the loss of both abilities of production and comprehension of language (Rothstein, 2005). Patients with global aphasia cannot do anything regarding language whether be it language articulation or be it language comprehension. They can only utter some syllables as a result of extensive damage to the left hemisphere (LH) of the brain. Regarding the prognosis of this type of aphasia, full recovery is rare.

One more type of aphasia is anomia that can be defined as the loss of the ability to name things. Surprisingly, a patient with anomia is able to recognize things and their usages, but is unable to say what they are called and this might be a result of aneurysm (a kind of developed aphasia) (Fridriksson et al., 2009). Primary progressive aphasia is a rare disorder where people slowly lose their ability to talk, read, write, and comprehend what they hear in conversation over a period of time. Patients with primary progressive aphasia are able to communicate in ways other than speech. Unlike primary progressive aphasia which is associated with cognitive impairments including many types of cortical and subcortical dementias, secondary progressive aphasia is correlated with memory impairments and attention disorders including anomic aphasia, conduction aphasia and dysarthria (Mesulam, 2001; Wilson et al., 2010; Harciarek \& Kertesz, 2011).

Isolation aphasia (also known as Mixed Transcortical Aphasia) is a sub-type of Wernicke's 
aphasia. Patients with isolation aphasia lose the ability to comprehend what is being said to them and have the difficulty in creating speech with meaning without affecting the ability to recite what has been said and to acquire newly presented words (Carlson, 2007). They can repeat what other people say, thus they do recognize words but they cannot comprehend the meaning of what they hear and repeat themselves. Pure aphasias are selective impairments in reading, writing, or the recognition of words. These disorders may be quite selective. For example, a person is able to read but not write, or is able to write but not read. Examples of pure aphasias are: Pure alexia, Agraphia, Auditory verbal agnosia (Kolb \& Whishaw, 2003). Other types of aphasia include: Dyslexia/ alexia (disability to read), dysgraphia/ agraphia (disability to write), child aphasia (common aphasia and developmental aphasia), crossed aphasia, and dementia (cognitive problems).

Existing literature traces Broca's aphasia to ancient Greece when, as a result of shocks and head injuries resulting from wars, some soldiers were unable to produce speech (al-Faramāwī, 2009). The 19th century witnessed some emphasis on it, when Mark Dax presented his article to Montpellier Medical Association (MMA) in 1836, in France. It was related to when he noticed that two patients were unable to speak. In 1861, the French Anthropological Association (FAA) had Bouillaud's pronouncements on the problem reported to it by his own son-in-law. That was "interesting to Paul Pierre Broca, who had two patients suffering from that disability at the time." (Columbia Electronic Encyclopedia, 2011, P1)

The area then got its name as BA after this French neurosurgeon. Thereafter, Broca's experiments on his patients concluded that an area in those patients' brain was damaged and that area was the center of language in their brain. On that basis, Broca's aphasia has been defined as the loss of the ability to speak after learning language (Learner, 1983) due to localized incurred cerebral damage in BA (Eisenson, 1973), which may also owe to Cerebral Vascular Accidents (CVA) (Shipley \& Mcafee, 2004), or other forms of disorder ('Alī \& Hasan, 2009).

The core task in BA is to determine what role played by this area in phonology, Syntax, word naming and picture selection. BA covers all aspects of expressive speech, which is in no way comparable with that of apes. More recent evidence, however, indicatesthat BA also goes wider in coverage than the area identified by Broca himself. It should also be noted that Broca's aphasia is different from Agrammatism - the former does not involve reading and speech comprehension, while the latter actually does (Whitaker, 1971). Similarly, the word Anarthria was emptied of its appropriateness to stand for Broca's aphasia at the tail of the 20th century (Marie, 1906), so Broca's aphasia is now the best term.

There is firm evidence for the neurolinguistic reality of the role played by BA in phonological and syntactic matters, notably syllables, nouns, verbs and sentences. Such important role is considered one of the most enduring issues in the neuroscience of language. In addition, any damage to BA results in aphasia, which is manifested in different forms, ranging from serious effort before speech (Davidoff \& Katz, 1985; Helm-Esta-brooks \& Rams-berger, 1986), a lot of stops and short telegraphic phrases (Whitaker \& Whitaker, 1976), to other forms. The 
primary goal of the present study is to shed light on how damage in BA affects language articulation, notably phonology and syntax of Arab Broca's aphasics. To this end, the researcher will examine certain syllables, nouns, verbs, and sentences in a Saudi Broca's aphasic to identify which one is impaired more.

Fundamentally, the extent and size of Broca's aphasia damage are determined by the size and type of the brain's lesion (Adas, 1998). Damage in the motor area will incapacitate the patient from writing, leading him to produce telegraphic-style speech involving omission (Kean, 1978; Caplan, 1985) and/or misselection (Grodzinsky, 2000). Other forms of incapacity have also been observed (Bonhoeffer, 1902; Salomon, 1914; Goodglass, 1968; Benson, 1976). Broca's Area (BA) and Wernicke's area (WA) of the LH of the cerebrum, which many neurolinguists accept as being locus of language functions, are relevant to our discussion, with BA as our focus in this study. Various neurolinguists have adopted different names for it, while actually referring to the same thing (Head, 1926; and Luria, 1964).

In sum, despite various forms and varying degrees of Broca's aphasia, it can be said that patients may comprehend everything, but that their speech production is affected at all levels. In other words and according to Ingalls (1945), "the individual can understand spoken language but cannot speak properly, even though the articulatory apparatus is apparently intact." (Ingalls, 1945, P.19)

\subsection{Aims}

The study attempts to answer the following questions:

1- A: How far does the damage in BA affect Arabic phonology and syntax? Which aspect is impaired more: is it the phonological aspect or the semantic one?

B: In comparison to each other, which of the following syntactic items is impaired more in Arab Broca's aphasics: single or compound proper nouns, present or past tense verbs, and affirmative, active or passive sentences?

2- It is claimed that Broca's aphasics have problems related to naming and selection. Are these problems limited to lexical items or they are extended to include pictures as well? Which one of the two abilities Arab Broca's aphasics suffer from more, compared with deficits in other syntactic and semantic aspects? Is there a relationship between such problems and sign language?

\subsection{Methodology}

The case under the question is a 53-year-old male with hypertension, and who is diabetic and is a heavy smoker. He had a stroke due to an occlusion in one of the branches of the Left Interior Frontal Lobe (LIFG) of the Middle Cerebral Artery (MCA). The result was that he developed sudden onset right weakness and inability to talk due to this cerebrovascular accident. Research data were prepared and analyzed, preceded by permissions from the family of the case at hand, from KSU and King Fahd Medical City (KFMC) represented by the External Research Review Committee (ERRC); the concerned sites at KFMC, including the relevant departments. However, the present study is both qualitative and quantitative. The 
case was observed over the time of study and periodically, throughout the study, qualitatively reviewing relevant persons - nurses, psychiatrists, SLPs, etc. The complexity of data collection led the researchers to undertake a windshield survey of information, followed by preparing them for analysis. After preparing the required documents, official letters, etc., the researchers started to visit KFMC wherein the case is hospitalized.

Several short tests were administered to the case by one of the researchers who interviewed him 4 times during 20 months (a visit per 4 months starting from December 2010 to December 2012). These tests sought to investigate language ability of the case, notably the phonological and syntactic aspects. These aspects include syllables (84), single proper nouns (10), compound proper nouns (10), present tense verbs (10), past tense verbs (10), affirmative sentence (10), active voice sentences (10), and passive voice sentences (10). Two more tests on word production (10 sentences) and selection (10 sentences) and picture naming (10 sentences) and selection (10 sentences) were also administered. The case's utterances were then transcoded by transliterating them using the transliteration system (Romanization) recommended by American Library Association- Library of Congress (ALA-LC), before they were analyzed by the researcher. Interviews were not only restricted to the case. The researchers had also interviewed guardians of pre and post-hospitalized patients.

\section{Literature Review}

\subsection{Introduction}

This section presents a review of literature related to the issues being addressed in this study. First, the historical background of Broca's aphasia is presented as well as information relating to neurolinguistic theories of BA. Research associated with developments in Broca's aphasia's programs is presented as well. In addition, information related to the relationship between damage in BA and language deficit are explored. Finally, neurolinguistic perspectives associated with Broca's aphasia are reviewed. Specifically, Arabic phonological and syntactic impairments within Broca's aphasics including syllables, nouns, verbs and sentences' problems are identified. Since our concern is with language articulation at the phonological and syntactic levels, our review will be selective, focusing on studies exploiting the above mentioned elements, especially those incorporating specific challenges to production due to phonological and syntactic complexity.

\subsection{Background}

Broca's aphasia began as a rather ambiguous concept when first introduced in the writings of 19th century's neurologists attempting to understand why some individuals had difficulty speaking. This dates back to the end of 1863 and to early 1864 where Broca was conducting an experimental study of eight (8) of his patients, trying hard to find a relationship that might exist between the loss of the ability to speak and the hemisphere that receives the lesion. After spending long period of time in observing those cases, he rightly observed:

"Here I am, watching eight cases for patients with lesion in the back part of the third frontal convolution. What drew my attention in all these patients is that the lesion is there in LH of their cerebrums and I dare not to declare these results, but I have to wait for new evidence." 
(al-Faramāwī, 2009, P. 104)

Broca, however, continued his experiments. Eventually, in 1864, it seemed that he was totally convinced of the importance of the $\mathrm{LH}$ as the site of language activities in the cerebrum (Columbia Electronic Encyclopedia, 2011, P.1). The next challenge for Broca was to prove or falsify his hypothesis. To that end, he continued his experiments, but this time on the right hemisphere. Finally he concluded that the articulatory region is in the LH and not in the right one and that it is the substrate (anchor) for language articulation. One of Broca's (1864) observations after the experiments he had done on the right hemisphere and the findings he had made is that:

"When doing the anatomy to some people, I have observed that they have a lesion in the right hemisphere of the brain, but those patients were not suffering from the loss of the ability to talk which means that the faculty of articulating language is localized in the LH or at least depends upon that part of the brain." (ibid. P.104)

\subsection{Theories of Etiology}

As a matter of fact, Broca has opened the door for all debatable arguments made by neurolinguists who came after him and discussed his theory. There is unanimity in most of his prolific findings and conclusions. Neurolinguists of the 20th century concentrated first on the cases of Broca's aphasia either through recognizing the symptoms or through examining what comes out of skull fracture (Head, 1926).

However, some neurolinguists at the second half of the 20th century started to design examinations to test and evaluate aphasics depending on obvious symptoms (Penfie, 1959). The first two stages dealing with the examinations programs designed for aphasics was introduced in 1884 by Jakobson (1963) who collected previous studies on the subject and examined them deeply. The aim was to determine whether or not there is a common factor between brain damage and linguistic ability and measuring that either within the same case (Howes, 1964) or in different cases (Lenneberg, 1973).

According to Darley (1964), Shuelle et al., (1964), and Smith (1971), neurolinguists started to theorize and analyze their assumptions in view of previous studies. Whitaker (1971) is one of those neurolinguists who did extensive research and analyses for all assumptions made by experts in the field. One of his findings is that BA tackles the role of language production along with most if not all other parts of the brain. According to him:

"The separate parts, sub-mechanisms or sub-systems of language in the human brain are connected with each other structurally and functionally i.e., anatomically and physiologically." (Whitaker, 1971, P. 93)

Commenting on the findings of Whitaker (1971), some neurolinguists emphasized that case studies' histories should be involved (Eisenson (1972, 1973; Yin, 1981). They concentrated on the cases that receive stroke. But what is the stroke? Nueolinguists almost made an agreement upon the lexical definition of the stroke in Stedman's medical dictionary. In his dictionary, Stedman defines the stroke as "a classical term for cerebral hemorrhage, 
thrombosis, embolism, or vasospasm usually characterized by some degree of paralysis." (Stedman, 1972, P.91)

Broca's aphasia's theories spawned the beginning of an increase in the identification of aphasics throughout Europe and the west within the last three decades of the 20th century. Neurolinguists started to apply the results recommended by theorists on their patients (Halpern, Darley, and Brown, 1973). The main purpose was to identify whether or not a relationship between mental handicap and language deficit exists (MacMillan, 1977; Jordan, 1989a; Hallahan \& Kauffman, 1994). It is for this reason that many comparative studies on aphasics and normal people are conducted to identify the similarities and dissimilarities between target groups. Such comparative studies helped neurolinguists to identify the problems of Broca's aphasics and record them. Based on the cases he deals with, Crystal (1980), for example, lists some of these problems and mentions them as follows: “...expressive, executive, production, motor, encoding, and non-fluent." (Crystal, 1980, P. 142)

Describing aphasics' speech, Geschwind (1971) as cited in Starkweather (1983) adds "...the content of their language is deficient." (Starkweather, 1983, P.309)

Howard et al., (2011) give more specific description of the speech by stating that Broca's aphasics "rely a lot on nouns" (Howard et al., 2011, P.147)

Based on the above mentioned findings, neurolinguists like Dworkin (1991) moved towards understanding whether or not one area in the LH is only responsible for all the above mentioned language impairments. One of the finding of Dworkin is that "Other zones like disparate cortical and subcortical sites including the supplemental motor cortex, basal ganglia and anterior limb of the internal capsule have been also implicated in the etiology." (Dworkin, 1991, P. 5)

Cornell et al., (1993) Cornell et al., (1998) stated that it was not until 1990s that BA came to be understood not only as a motor speech area, but also as an area which is involved in comprehension tasks. Using standard Serial Reaction Task, (SRT) to investigate learning procedure both for spatio-motor and phoneme sequences in Broca's aphasics, results of Goschke and his colleagues (2001) support the assumption that some parts of the brain system are involved in such procedures.

This finding of the complex role of BA inspired Watkins et al., (2004) to publish an article about examining this area using imaging techniques. They combined Positron Emission Tomography (PET) with Transcarnial Magnetic Stimulus (TMS) to locate which area is responsible for modulation of excitability of the motor system during speech. Gil-da-costa et al., (2006) attempted to compare human brain with the brains of some animals, notably apes. The team used PET as a tool to discover such relationship. In fact, Gil-da-costa and his colleagues opened the door for other curious researchers who came later to participate in such solutions (keller et al, 2009; Amunts et al., 2010; petrides \& Pandye, 2010; and Taglialatela et al. 2011). 


\subsection{Related Studies}

This part reviews studies conducted on the relationship between Broca's aphasia and oral communicator abilities. It also casts light on the means of treatment. Investigating the lexical processing functions in many regions in the brain including BA, Fiez (2011) pointed out that in patients with damage in BA, articulatory as well as phonological deficits have been reflected. These findings actually were supported two years later (Hallahan \&Kauffman, 1994). Studies mapping BA found out that it is also directly or indirectly involved in some functions of other regions and /or sub-regions in the left of the cerebrum. The articles described syntactic impairments including perceptual ambiguity (Demonet, 2011) and autonomy of syntactic processing (Friederici, 2011).

In addition, Raw's research (1997) demonstrated that significant articulation symptoms could exist in Broca's aphasics with average and even above-average intellectual abilities. He brought an example from real life for an aphasic who described his case while being awarded National Aphasia Association (NAA) prize. According to this person, when he was aphasic, his only answer was "Yes" for everything he wanted to say even when he wanted to say "No" (Crowe, 1997). Philips \& Ruscello (1998) mention other symptoms that Peach (1998) observed in six of his cases. The symptoms included higher-order ability disruption, benign-to-malignant mixed non fluency, and noticeable declination both in verbal and nonverbal intellectual abilities.

Further studies would seek to determine neurological causes for the condition. Using PET, Musso et al., (2011) prove that Middle Cerebral Artery (MCA) is involved in language activities performed by language area in the LH of the cerebrum and these results were supported by some other studies, notably those used diagnostic examinations like Boston Diagnostic Aphasia Examination (Goodglass et al., 2000; Radanovic \& Mansur et al., 2007).

Statistical research contributed to heightened clinical and social awareness to the phenomenon of Broca's aphasia. Even though they were neurolinguists, Kauhanen et al., (2000) would extend their commitment to addressing Broca's aphasia beyond the clinical realm. The team prove that $36 \%$ of 106 of those patients who were diagnosed as aphasics continued to be aphasics 12 months later. These findings reveal an important part in the life of aphasic patients, which is that there is a psychological phase represented by "suffering" which may continue for 12 months as we have seen here and which may become permanent in some others. Psychologically speaking, the patient almost loses most of his social life due to the fact that he has become a non-oral communicator (Simmons, 2001). In spite of that, some others may continue to struggle, realizing that being aphasic does not mean the end of the world. These are the ones who are supported and enhanced by their family members and are more likely to improve than others who are not similarly supported by their families. As cited in Grodzinsky (2000), the right has the right to inquire into the neurological factors that could contribute to Broca's aphasia in the 1920s and 1930s. Grodzinsky criticized Broca's theory (hypothesis) counter-arguing that the Left Anterior Cortex (LAC) is not the place 
where most of human linguistic abilities are located. The evidence brought by Grodzinsky is based on the fact that BA has nothing to do with vocalic system and paralinguistic signals, namely gestures. These results did not receive high support by Milhim (2002) who insist that LAC is the region where most of human linguistic abilities are exist and that any damage to this place in BA is considered "a direct cause of speech disorders." (Milhim, 2002, P. 190)

Both arguments of Grodzinsky (2000) and Milhim (2002) were developed regardless of the unanimity made about the dominance of the $\mathrm{LH}$ as handedness here is a relative issue for them (Beaton, 2011). Comparing Broca's aphasia group to another control group, Ter Keurs et al., (2002) found that delayed availability of word- class information is of special importance as Broca's aphasics showed no early vocabulary class (VC) effect and also no late anterior shift towards closed system. Depending on Barlow's case of 1877, Buckner et al., (2011) would continue to conduct their research on Broca's aphasics, realizing that Homologous regions in the RH can take over BA's role in a case where it is damaged, and this result was later supported by some other studies, but this time with the use of Functional Magnetic Resonance Imaging (fMRI) (Mahdavi et al., 2008; Plazza et al., 2009).

In fact, these results motivated the neurolinguistic researchers to go deeper inside BA. They discovered that the interaction between biological constraints and language experience in this region enabled linguistic competence for a new language (Musso et al., 2003). This interaction is made by chains of neurons. According to Healy (2004), "the chains of neurons are what make the connections and allow the neurons' their ability to talk among themselves." (Healy, 2004, Introduction)

Musso and his associates also found that deficit in verbs -be they the main or auxiliary verbs- is not based on the position where certain structures take place in the syntactic tree (Bastiaanse \& Thompson, 2003). This discovery inspired others to develop a treatment approach to improve word retrieval, namely, for chronic Broca's aphasic patients (Conley\& Coelho, 2003).

Scientifically speaking, any hypothesis by definition can be falsified, especially when talking about neurolinguistic issues, because most of those things said about neurolinguistics are debatable and controversial. Besides, understanding the brain and its functions is too complex. Strictly, what we know about the brain is just a scratch on the surface, which is why we need neurologists to be involved in most if not all our studies. Nonetheless, many questions are left unanswerable. For example, how do aphasics recover? Is it the capability of the brain to heal itself (plasticity feature) proposed by Bruel-Jungerman et al., (2007) based on the results of the longitudinal study of Tanner (2003) where four aphasic patients were recovered? Does Right Hemisphere (RH) have something to do with this (Equi-potentiality theory suggested by Flourens 1825 and later revised by Lashly 1950s)?

What neurolinguists are sure of is that the left hemisphere is responsible for language. Summarizing the functions of the left hemisphere of the cerebrum, Spreen \& Risser (2003) have clearly listed some of them by stating that ".... poor speech production, Agrammatism, 
anomia, and verbal paraphasia, with relative comprehension, involving mainly the left frontal areas.” (Spreen \& Risser, 2003, P.5)

Neurolinguists, as can be seen, made it clear that what they know about the brain is just a scratch on the surface. It is for this reason, however, that they tend to concentrate on the cases themselves in their investigation. For example, Parr (2003) studied the case of a patient called Clarke who had received a stroke in his LH causing him to become aphasic for a while till he recovered later. Shortly after his recovery, Clarke describes his situation immediately after the accident, Clarke stated:" ... Struggling to the phone and calling a friend only brought more fearful confusion. As I tried to tell him my problem, I realized I was not making sense. I was not talking. Time and again I tried, but no words would come, not even my own name, just this jumbled panicky" (Parr, 2003, Pp.81-82).

In fact, BA proved to be responsible for many language disorders. For example, Broca's aphasics show sensitivity to pragmatics (Nakano \& Blumstein, 2004), syntactic processing during sentence comprehension (Wassennar et al., 2004). This syntactic processing, according to neurolinguists, is a result of the way the verb is produced because verb production -be it in word or in sentence- is notoriously difficult for Broca's aphasics. Bastiaanse \& Van Zonneveld (2004)'s study concludes by suggesting the use of Levelt's "grammatical encoder" to locate the functional impairment in Broca's aphasia. Others suggested Linguistic Specific Treatment (LST) as it provides more benefit for Broca's aphasics (Murray et al., 2004). The studies mentioned above proved that BA is undoubtedly involved in language representation (Molnar-Szakacs, 2011) although some researchers claim that BA has no pivotal role in some language's aspects like imitation, for example (Michiru, 2011).

With the passage of time, neurolinguists also realized that Broca's patients have difficulty even to detect on-line violations of word- category in case the word class information is incomplete or delayed (Wassenaar et al., 2005). Bastiaanse \& Van Zonneveld (2005) examined the ability of Broca's aphasics to produce transitive sentence (The boy breaks the glass) and intransitive sentence (The glass breaks). Results show that Broca's aphasics are better in producing the former than the latter. Such deficits are results of brain abnormality which Broca's aphasics go through. This abnormality leads to weakness not only in articulatory apparatus, but also in neurons' function. As cited in 'Abdul-Lațīf (2005), Bert summarized what Broca's aphasics suffer from using the term "general weakness." ('Abdul-Latīif, 2005, P.74)

According to Druks \& Carroll (2005), Bastiaanse and his associate demonstrate the crucial role of tense in Broca's aphasia, notably reflective forms like those of past tense (Barber et al., 2005). Further research into the understanding of BA has resulted in examining researches' outcomes against theories. Caramazza's et al., (2005), for example, examined Trace Deletion Hypothesis (TDH) which contends that Broca's aphasics perform active sentences than passive ones. Results of Caramazza and his team failed to prove this hypothesis when they 
applied it to 38 Italian cases. These results encouraged some other researchers to investigate means of treatments. According to Abu Hâtim (2005), continuous training of speech organs is considered a means of treatment that should be used "under the supervision of SLPs." (Abu Ḥātim, 2005, P.62)

In case if it fails, Abu Hātim (2005) adds: "one can resort to other alternative means of communications." (ibid. P.62)

In response to such results, (2005) proposed the use of Repetitive Transcranial Magnetic Stimulation (RTMS) as a tool of therapy. Roth \& Worthington (2005) used the examination of Goodglass and his colleagues (2000) to prescribe Broca's aphasic who had been asked to describe a picture. The case's utterances were as follows:

" ...uh...mother...uh... she talking to the... uh... the... uh...I don't know...two cup...cookie in jar...fall down...wash... and stool... uh... tipping...by ...uh ...get hurt."

(Roth \& Worthington, 2005, Pp.216-220)

In 2005, Novick published an article about the role played by BA in matters concerning sentence processing in the light of cognitive control. One of the findings of the study shows that Left inferior frontal gyrus (LIFG) in BA has a significant role as it helps in re-analyzing facial misinterpretation. Results of the study led to a neurolinguistic mandate to review and assess Novick's findings to identify the role of BA in syntactic issues including verbal memory (Ghislaine et al., 2006), word in context (Bendy, 2007) and to make recommendations. Such outcomes could be found in experimental studies where large number of population is used and aphasia's rate is clearly stated. Engelter et al., (2006) conducted a study of this nature on 188, 000(One hundred and eighty eight thousand inhabitants). Results demonstrate that that aphasia's rate attributed to first ever ischemic stroke is $43 \% / 100,000$ American inhabitants with an increase of $4 \%$ / year.

Gentilucci et al., (2006), Vasié et al. (2006) and Skipper et al., (2007) identified the role played by BA in the process of translating body gestures into speech aspects and assigning possessive pronouns in elided verb phrase. Other researchers have investigated the syntactic and phonological roles played by BA in addition to other roles. These roles include lexical naming (Singla et al., 2007), picture naming (Scott \& Wilshire, 2010; Kang et al., 2011; (Semenza et al., 2011), word selection (Bendy et al., 2007; Heim et al, 2011b), sentence-picture mismatches (Wassenaar et al., 2007) and articulation (Terao et al., 2007).

Research using brain scan analysis has found that specification of BA required from 2-3 years of postnatal life for its gradual completion (Judas \& Cepanec, 2007). Furthermore, brain imaging studies have shown a significant connection between this area and other parts of the brain, notably diagonal sulcus posterior Sylvian fissure (Keller et al., 2007; Cantalupo\& Hopkins, 2007). In the main, these parts also showed a significant increase in activity with increases in language production. Such findings, according to Dickey \& Thompson (2007) explain why both syntactic and morphological structures are impaired at the same time in many cases. 
Unlike studies that compared the speech of cases with Apraxia of Speech (AOS) to the fluent speech of control group (s) (Keith et al., 2006; Ogar et al., 2006), Van Lieshout et al., (2007) compared motor control strategies for the speech production of a woman suffering from AOS and Broca's aphasia to a control group. One of the conclusions of Van Lieshout and his colleagues is that there is a potential association between the stability of coordinative patterns and the range of articulation organs' movements.

In 2007, Beversdorf et al., and Bakheit et al, published yet another series of articles on the subject of Broca's aphasics and means of treatment, pointing out that some energy system is found to be very helpful for Broca's aphasics like Propranolol, which is found to be better than Placebo in improving naming in these patients. The studies recommend of the permanent observation for Broca's aphasics who found to have the best prognosis for improvement of language function in the first year of stroke.

The groups included speaker's discourse signals (paralinguistic signals) including mimes, gestures, body actions, facial expressions, etc., which found to play a prominent role in the listener's feedback due to elicitation on his/ her motor plan (Skipper et al., 2007). During the 2007, most research on BA was not only confined to the influence of this area of interpreting speech phonetically, it expands to include lexical decision making as well (Heim, et al., 2011a). Given the proliferation of research in BA and the lenses through which the various roles of this area in phonology and syntax are viewed, specific roles remain problematic.

The scientific diversity of researchers conducting work related to BA has expanded over the past years of the first decades and the first years of the second decades. Moreover, several Magnetic Resonance Imaging (MRI) studies have shown that some other areas like lateral surface and medial regions in the left part of the brain are responsible for language articulation rather than BA. According to researchers, BA now is broader than the area identified by Broca himself in the 19th century (Dronkers, et al., 2011; Price, 2009) which is therefore considered to be crucial for the development of BA studies.

Consequently, relevant information is being generated from a wide spectrum of research areas. Research findings on BA are now being published from fields such as linguistics, education, and speech language pathology. For example, it is now known that Broca's aphasia is "more common in men (37\%) than in women (28.3\%)." (Cummings, 2008, p. 342)

With more research in the field, the need for new ideas and suggestions on Broca's aphasia becomes even more acute. Patel et al., (2008) suggest using implicit and explicit tasks as tools to investigate musical syntactic processing that lacks a systematic investigation. The idea of conducting a systematic research attracted some researchers like Eiling et al., (2008) who attempted to specify the role of LIFG to certain semantic aspects. Based on evidence from eye movement experiments, Eiling and his colleagues concluded that such a role depends on the pattern of deficit.

Using mouse models of Middle Cerebral Artery Occlusion/ Reperfusion (MCA/OR) and Experimental Autoimmune Encephalomyelitis (EAE) to examine the influence of the deficits of Central Nervous System(CNS), including strokes and their effects on language, cognitive 
ability, and other functions, Zhang(2011) points out that changing activation pattern of Cannabinoid (CB1) and CB2 affects the outcomes after MCA's impairment.

From a clinical perspective, some neurolinguists in the field of Broca's aphasia are starting to research and publish the positive aspects of Broca's aphasia. These publications are beginning to broaden the understanding of the condition of Broca's aphasia and are consequently having a more positive impact on Broca's aphasics as we currently understand them. Sārkāmū et al., (2008) suggest listening to music as at, according to the team helps in cognitive recovery when applying it directly after left MCA stroke; similar results were supported two months later by another such study carried out by the University of Helsinki's Illuminate Research (UHIR) in angiology (2008). Unlike Sārkāmū et al., (2008)'s study, Schlaug et al., (2008)'s study suggested singing lyrics justifying that Broca's aphasics would prefer singing to speaking, and that's what led to developing Melodic Intonation Therapy (MIT).

Ragalsky's research (2008) proposed that to fully understand the role played by BA in all its complexity and individual patterns, we must start with a clear and accurate understanding of what BA is, and furthermore, what is the relationship between this area and other regions in the LH. The functional relevance of BA and other different regions in the LH as revealed by functional magnetic resonance imaging (fMRI) has led to assess the role played by BA and Anterior Temporal Lobe (ATL). Results of Ragalsky's research show that sub-regions of BA are involved in increased activities of syntax, while ATL regions are involved in hierarchal structures process in general and in sentence process in particular. Part of these results comes from another study conducted by Makris \& Pandya (2009) where Diffusing Tensor Magnetic Resonance Imaging (D-T MRI) technique is used. According to Makris \& Pandya, possible role played by extreme capsule $(\mathrm{EmC})$ in language areas including BA in matters concerning language is observed.

In addition, the use repeat perfusion weighted imaging technique to test Broca's aphasics is thought to determine the suitable means of treatment. Davis et al., (2008) proved that it depends on blood flow, where we make sure that language functions become impaired when BA is dysfunctional and recovered when it is functional, which again provides strong evidence that BA's role in matters relating to language function is essential. These results are supported by Fridriksson et al., (2008)'s study. In fact, this connectivity in brain's functions supports the theory of holistic approach holders (Tsapkini et al., 2008). Understanding such approach allows us to understand different precise roles played by BA like its role in tenses, namely, verbs more than nouns (Cappelletti et al., 2008).

Schnur et al., (2009) reported a relationship between BA and music. According to Schnur and his associates, music can be used as a means of treatment for Broca's aphasics. More specifically, between LIFG and music execution, notably after the role of posterior part of this gyrus is investigated (Fadiga et al., 2009). Today, many new techniques are found to be useful in predicting the type of impairment in Broca's aphasics which allows for better treatment like intracranial electrophysiology. This technique shows that linguistic processing sequence including lexical, grammatical and / or phonological can be predicted on 
computational grounds (Sahin et al., 2009). Transcranial Magnetic Stimulation (TMS) is another technique through which one can determine what role LIFG plays in the encoding of grammatical gender (Cattaneo et al., 2009). Diffusion Tensor Magnetic Resonance Imaging (DTI) provides the role of BA in both natural and artificial language where researchers observed an increasing Fractional Anisotropy (FA) in fibers arising from BA (Floel et al., 2009). It also shows what role BA plays in neural and psychological organization of the system of language processing (January et al., 2009).

Keller et al., (2009) maintained that research is beginning to reveal that there are in fact opposite viewpoints that support researchers who minimized the role of BA in language articulation. According to Keller and his associates, these researchers claim that circumscribed definition of BA is dissociated from Broca's aphasia. They built their evidence on the fact that anatomical gross of BA varies between people, thereby reflected on the various definitions between studies (Keller et al., 2009).

Such assumptions are falsified with the tremendous development in imaging techniques that revealed the cover, not only on the different roles played by BA like its role in morphosyntactic deficit (Venkataraja et al., 2009), tenses (Jonkers \&de Bruin, 2009), namely, verbs (Thompson \&Lee, 2009), but also in putting an end to the issue whether or not there is a relationship between Broca's aphasia and any other disease (Commondoor et al., 2009). The studies of imaging techniques are fairly recent when compared to other scientific inquiries. Moreover, they helped others like Speech Language Therapists in developing the appropriate treatment, taking into consideration all various factors including age, the time when a person acquired his L2 ( Bloch et al, 2009; Tschirren et al., 2011 ).

The majority of the research has been focused on identifying and developing theoretical ideas about the main role played by BA. Fazio et al. (2009) investigated other roles played by BA. Results of the study demonstrate that BA is not only limited to language articulation; rather, it has a minor role in understanding individuals' actions. More recently, studies began focusing attention on imaging techniques to determine the ability of Broca's aphasics to word naming selection task. Conclusions drawn from the study of Heim et al. (2011a) show that repetition priming is positive at the level of syntactic and semantic selections, but negative at the level of phonological selection.

BA is also connected to medial frontal cortex, that is, Broadman's area. The significance of this relation is that it helps some researchers to locate precisely the roles played by anterior and posterior BA. According to Ford et al., (2010), it was suggested that the former is responsible for semantics while the latter is responsible for syntax and /or phonology. Understanding such relationship helps speech language therapists in selecting the suitable treatment for their Broca's patients. As cited in al-Imām\& al-Jawāldah (2010), alal-Jawāldah (2008) has clearly stated "it is necessary to design programs." (al-Imām\& al-Jawāldah, 2010, P.321)

"Lee Program" is one of these suitable programs which, according to al-Khașāwnah et al., (2010) designed for those "who feel shy if they cannot articulate words correctly." 
(al-Khașāwnah et al., 2010, P.245)

Carrying out a longitudinal case study on a client with chronic Broca's aphasia (7-year period) to see the effect of long-term therapy on treating case's impairment, Stark (2010)'s study suggested that long-term provision of therapy has led not only to verbal communication skills improvement, but also to the enhancement of the quality of life, and this suggestion was supported by other studies (Stark, 2010; Boo et al.2011; Lazar \& Mohr, 2011).

Tyler et al., (2011) recorded findings that suggest LIFG may not itself be responsible for such a process, but play a pivotal role in the neural network that carries out computations of syntax. The researchers stated that tissue integrity and neural activity mainly in left Broadman area 45 and posterior middle temporal gyrus were associated with preserved syntactic performance. Furthermore, it is found to be involved in implicit motor sequence learning (Clerget et al., 2012).

In contrast, this unanimity on the role of LIFG was not supported by Bizzi et al., who in (2012) discussed the role of Ventral Precentral Gyrus (VPCG) and the Arcuate fasciculus (AF) in language articulation and their relationship with gliomas, resulting that gliomas growing in the left VPCG are much likelier to cause Broca's aphasia than those of LIFG, and that AF offered a fertilized environment for the appearance of aphasia.

\subsection{Conclusion}

The study of Broca's aphasia has passed through three stages of evolution. The first stage is related to the 19th century where BA was first identified by Broca himself. The second stage takes place in the first half of the 20th century where different theories about the phenomenon started to be released. The final stage of the evolution of Broca's aphasia's studies began in the second half of the 20th century, notably in the 1970s extending into the first decade of the 21 th century. These evolution stages opened up the study of BA to neurologists, neurolinguists, psychoneurolinguists, and SLPs and led to a substantial breadth of research in the field and, consequently, a variety of clinical, research, and neurolinguistic approaches to understanding the condition of Broca's aphasia.

Extensive research on the role played by BA in language articulation was conducted in the last few decades. Numerous studies have attempted to characterize the boundaries of BA. The focus of researches from different languages was on the phonological and syntactic production and impairments relating to them. These include: Articles (Swedish: Manson\& Ahlsen, 2001; Dutch: Havik et al., 2004), Active-passive sentence production (Arabic: Faroqi-Shah, 2003; Dutch and German: Bastiaanse \& Van Zonneveld, 2004; Italian: Caramazza et al., 2005), pronouns (Dutch: Ruigendijk \& Baauw, 2007), simple verbs inflection (Spanish: Centeno, 2007), finite verbs (Dutch: den Ouden et al., 2008), word order in verb final sentence (German: Bornkessel-Schlesewsky et al.,( 2009).

Some researchers have used imaging techniques to observe activities of BA and the effects of these activities on testing syntactic processing in Broca's aphasics (Dutch: Burkhardt et al., 2008; Persian: Mahdavi et al., 2008). Some have shown problems related to WH-questions (Dutch: Neuhans et al., 2008), the inverse patterns (Dutch: Bastiaanse \& Van Zonneveld, 
2006; Italian: den Ouden et al., 2008; Indonesian: Anjaningish \& Bastiaanse, 2011). Others concentrated on the phonetic as well as the phonological problems and issues related to them like complex articulatory movements (Chinese: Zhang et al., 2011).

It is a different story, however, when the attention turns to the software programs that should be designed based on practical experiences in speech production of Broca's aphasics; some neurolinguists produced some software that may help train speech production in this regard. These programs include ACTION (Bastiaanse et al, 2006; Bastiaanse et al, 2004; Links et al, 2010) that has been developed to train those who have problems in producing verbs. Cerebrolysin is also found to be effective in treating patients with Broca's aphasia, namely, those of LMCA - (Jianu et al., 2010), Electromagnetic Articulography (Kotz et al., 2010), rTMS (Platz et al., 2010).

Burns \& Fahy (2010) made the argument that LIFG is an essential player in lexical, phonological and grammatical production 'mirror mechanism'. Motor speech system is not necessary for speech comprehension but may play a role in orthographic decoding and/ or in auditory-visual matching of phonological forms (Hickok et al., 2011). The same thing applies to Non-invasive Brain Stimulation technique (NBST) including Transcranial Magnetic Stimulation (TMS) and Transcranial Direct Current Stimulation (tDCS) (Schlaug et al., 2011; Cattaneo et al. 2011). When it comes to describing accurate diagnostic tools designed for Broca's aphasics, MEG and fMRI studies indicate that instruments like Bilingual Aphasia Test (BAT) and Boston Diagnostic Aphasia Examination (BDAE-SF) yield highly comparable results (Peristeri et al., 2011; Pang et al., 2011).

As a result of the success achieved by using of Repetitive Transcracial Magnetic Stimulation (rTMS) up to 43 months post stimulation, Barwood et al., (2011) investigated the application of rTMS associated with electrophysiological correlates through semantic measurements. Results of the study showed a capacity of rTMS in modulating neural language networks, and measuring the lexical-semantic functions of Broca's aphasics. After the success of using mapping therapy in treating Broca's aphasics in matters concerning syntax (Hickok et al., 2011).

Other studies recommended using programs developed by experts in the field as means of treatment for Broca's aphasics. According to them, these programs are found to be useful for treating language deficit in Broca's aphasics including morphological-syntactic impairments (Marková \& Cséfalvay, 2010), past tense production (Harris et al., 2012), artificial grammar (de Vries et al., 2010), regular past-tense morphology (Justus et al., 2011), word and /or phonotactic frequency (Grande et al., 2011; Vaden et al.,2011), and language comprehension (Kotz et al., 2010; Duman et al, 2011).

In summary, the higher order thinking of the role played by BA in matters concerning language production, notably phonological and syntactic aspects makes an early appearance in the field of neurolinguistics across the world. Hundreds of researches throughout the last century investigated this linguistic phenomenon from different angles. The purpose was to diagnose Broca's aphasia neurolinguistically to see to what extent damage in this area affects language articulation, notably the phonological and syntactic aspects, including syllables, 
nouns, verbs and sentences.

Additionally, some of those studies investigated skills' ability of Broca's aphasics. Again, the aim was to identify the relationship between BA and certain skills like word production and picture naming and selection. Furthermore, those who demonstrated significant signs of the disorders participated in different life skills program designed to help them deal more effectively with their disorder. Recent outcome data from Broca's aphasia's therapeutic programs indicated that the impairments rate among Broca's aphasic was decreased.

Such conclusions lead to reactions among researchers of the new generation. Based on the above findings, the researcher hypothesizes that Arabic phonological and syntactic aspects are different from those of other languages because of the distinctive features of Arabic language in comparison to other languages. In response to this hypothesis, he decides to undertake this study.

Since no study had been conducted to investigate this neurolinguistic phenomenon, Broca's aphasia, in KSA, the principle aim of the current study is to examine the role of BA in language articulation. Specifically, it attempts to shed light on Arabic phonological and syntactic aspects including syllables, nouns, verbs and sentences that Broca's aphasics normally suffer from. The ability of Arabic Broca's aphasics to name and select words and picture will also be explored.

The researcher predicts that the conclusions drawn from this study may partially agree with results of other studies in matters concerning the disability of Arabic Broca's aphasics to recognize words and select pictures, but may not agree with them in issues related to phonology and syntax. This hypothesis will be tested in the present study which will be supported by a full analysis of the speech of the case at hand. It is hoped that the results of the study would contribute in enriching scientific research about such neurolinguistic phenomena like the one at hand. The challenge is to maintain an environment that fosters the neurolinguistic researches because this type of research is the precursor of innovative research in the field not only in KSA, but also in the Arab world.

\section{Data Analysis}

\subsection{BA and Arabic Phonology and Syntax}

There is no evidence whether or not the mechanisms followed by linguistic or computational models to articulate grammatically correct speech is the same or at least similar to the mechanisms used by the brain of human being. Many questions relating to how language is represented in the brain remain unanswered. What psychoneurolinguists, SLP/Ts and other language experts are sure of today is that any damage to BA results, undoubtedly, to language impairment, notably in the phonological and syntactic aspects. This is the clue through which neurolinguists now and then know about how BA is involved in language and speech and, more importantly, how this part in the LH of the brain came to be known as "Broca's Area".Strictly, BA is found to be involved in phonology and syntax, and Arabic language is not an exception. 


\section{Ml Macrothink}

Before discussing the relationship between BA and Arabic phonology and syntax in more detail, the relevant two aspects are briefly characterized with respect to their grammatical distinctive features. This brief characterization provides an important context for the review of the study's findings on how damage in BA affects Arabic phonology and syntax. However, the nature of the relation between damage in BA and phonological and syntactic deficit in Arab Broca's aphasics, though under extensive study in recent years, is still controversial and needs to be fully specified. The current study explored the nature of this relation.It is found in many studies that the phonology and syntax of the aphasic patient is affected. In order to in/validate such results in Arabic, the researchers examined the phonological and syntactic aspects of the case under question.

\subsubsection{Phonological Aspect}

\subsubsection{Syllables}

Standard Arabic has 28 alphabet. Arabic 28th alphabet were syllabified into three each (based on Arabic famous rules of alphabetical syllabification) and the case was asked by one of the researchers to repeat them one by one in all five visits. The total number of syllables is 84 . The researcher's speech is considered as a model. It was given the total score (5) at the scale of five (5). The case's scores were compared to the researcher's pronunciations and judged against the above mentioned scale. The following table illustrates the case's performance in phonology, notably syllables in thewhole five visits. Consider:

Table 1. Syllables'Production: Outcomes of five (5) visits.

\begin{tabular}{|c|c|c|c|c|c|c|c|c|c|c|c|c|c|c|c|}
\hline No. of Visits & \multicolumn{5}{|l|}{ 'a } & \multicolumn{5}{|l|}{ i } & \multicolumn{5}{|l|}{ 'u } \\
\hline & 5 & 5 & 5 & 5 & 5 & 0 & 5 & 5 & 0 & 0 & 0 & 0 & 0 & 0 & 0 \\
\hline & \multicolumn{5}{|c|}{ ba } & \multicolumn{5}{|l|}{$\mathrm{bi}$} & \multicolumn{5}{|c|}{$\mathrm{bu}$} \\
\hline \multirow[t]{2}{*}{$1-5$} & 0 & 5 & 0 & 5 & 5 & 0 & 5 & 5 & 0 & 0 & 0 & 0 & 0 & 5 & 0 \\
\hline & \multicolumn{5}{|l|}{ ta } & \multicolumn{5}{|l|}{$\mathrm{ti}$} & \multicolumn{5}{|l|}{ tu } \\
\hline \multirow[t]{2}{*}{$1-5$} & 0 & 0 & 0 & 5 & 5 & 0 & 5 & 5 & 5 & 0 & 0 & 0 & 0 & 5 & 0 \\
\hline & \multicolumn{5}{|c|}{ tha } & \multicolumn{5}{|c|}{ thi } & \multicolumn{5}{|c|}{ thu } \\
\hline \multirow[t]{2}{*}{$1-5$} & 0 & 0 & 5 & 5 & 5 & 0 & 5 & 5 & 5 & 0 & 0 & 0 & 0 & 5 & 0 \\
\hline & \multicolumn{5}{|c|}{ ja } & \multicolumn{5}{|l|}{$\mathrm{ji}$} & \multicolumn{5}{|l|}{ ju } \\
\hline \multirow[t]{2}{*}{$1-5$} & 0 & 0 & 5 & 5 & 0 & 0 & 5 & 5 & 5 & 0 & 0 & 0 & 0 & 5 & 0 \\
\hline & \multicolumn{5}{|c|}{ ha } & \multicolumn{5}{|l|}{ hi } & \multicolumn{5}{|c|}{ hu } \\
\hline \multirow[t]{2}{*}{$1-5$} & 0 & 5 & 0 & 5 & 0 & 0 & 5 & 5 & 5 & 0 & 0 & 0 & 0 & 5 & 0 \\
\hline & \multicolumn{5}{|c|}{ kha } & \multicolumn{5}{|c|}{ khi } & \multicolumn{5}{|c|}{ khu } \\
\hline \multirow[t]{2}{*}{$1-5$} & 0 & 0 & 5 & 5 & 5 & 0 & 5 & 5 & 5 & 0 & 0 & 0 & 0 & 5 & 0 \\
\hline & \multicolumn{5}{|c|}{ da } & $\mathrm{di}$ & & & & & $\mathrm{du}$ & & & & \\
\hline $1-5$ & 0 & 0 & 0 & 5 & 5 & 0 & 5 & 5 & 5 & 0 & 0 & 0 & 0 & 5 & 0 \\
\hline & $\mathrm{dh}$ & & & & & $\mathrm{dr}$ & & & & & $\mathrm{dh}$ & & & & \\
\hline $1-5$ & 5 & 0 & 0 & 5 & 0 & 0 & 5 & 5 & 0 & 0 & 0 & 0 & 0 & 5 & 0 \\
\hline & $\mathrm{ra}$ & & & & & ri & & & & & $\mathrm{ru}$ & & & & \\
\hline $1-5$ & 0 & 0 & 5 & 5 & 5 & 0 & 0 & 5 & 0 & 0 & 0 & 0 & 0 & 5 & 0 \\
\hline & $\mathrm{za}$ & & & & & zi & & & & & $\mathrm{zu}$ & & & & \\
\hline $1-5$ & 0 & 0 & 0 & 5 & 5 & 0 & 0 & 5 & 5 & 0 & 0 & 0 & 0 & 5 & 0 \\
\hline & sa & & & & & si & & & & & $\mathrm{su}$ & & & & \\
\hline $1-5$ & 0 & 0 & 0 & 5 & 0 & 0 & 5 & 5 & 5 & 0 & 0 & 0 & 0 & 5 & 0 \\
\hline
\end{tabular}




\begin{tabular}{|c|c|c|c|c|c|c|c|c|c|c|c|c|c|c|c|}
\hline \multirow[b]{2}{*}{$1-5$} & \multicolumn{5}{|c|}{ sha } & \multicolumn{5}{|l|}{ shi } & \multicolumn{5}{|c|}{ shu } \\
\hline & 0 & 5 & 0 & 5 & 0 & 0 & 5 & 5 & 5 & 0 & 0 & 0 & 0 & 5 & 0 \\
\hline & \multicolumn{5}{|l|}{ șa } & \multicolumn{5}{|l|}{ și } & \multicolumn{5}{|l|}{ șu } \\
\hline \multirow[t]{2}{*}{$1-5$} & 0 & 0 & 0 & 5 & 0 & 0 & 5 & 5 & 5 & 0 & 0 & 0 & 0 & 5 & 0 \\
\hline & \multicolumn{5}{|l|}{ da } & \multicolumn{5}{|l|}{ di } & \multicolumn{5}{|l|}{$\mathrm{du}$} \\
\hline \multirow[t]{2}{*}{$1-5$} & 0 & 0 & 0 & 5 & 0 & 0 & 0 & 0 & 5 & 0 & 0 & 0 & 0 & 0 & 0 \\
\hline & \multicolumn{5}{|l|}{ ta } & \multicolumn{5}{|l|}{$\mathrm{ti}$} & \multicolumn{5}{|l|}{ tu } \\
\hline \multirow[t]{2}{*}{$1-5$} & 0 & 0 & 0 & 5 & 0 & 0 & 0 & 0 & 5 & 0 & 0 & 0 & 0 & 0 & 0 \\
\hline & \multicolumn{5}{|l|}{ za } & \multicolumn{5}{|l|}{ zi } & \multicolumn{5}{|l|}{$\mathrm{zu}$} \\
\hline \multirow[t]{2}{*}{$1-5$} & 0 & 0 & 0 & 5 & 0 & 0 & 5 & 0 & 5 & 0 & 0 & 0 & 0 & 5 & 0 \\
\hline & \multicolumn{5}{|l|}{ 'a } & \multicolumn{5}{|l|}{ 'i } & \multicolumn{5}{|l|}{ 'u } \\
\hline $1-5$ & 5 & 5 & 5 & 5 & 0 & 0 & 0 & 5 & 5 & 0 & 0 & 0 & 0 & 0 & 0 \\
\hline & gha & & & & & ghi & & & & & ght & & & & \\
\hline $1-5$ & 0 & 5 & 0 & 5 & 0 & 0 & 0 & 0 & 5 & 0 & 0 & 0 & 0 & 5 & 0 \\
\hline & fa & & & & & $\mathrm{fi}$ & & & & & $\mathrm{fu}$ & & & & \\
\hline $1-5$ & 0 & 0 & 0 & 5 & 0 & 0 & 5 & 5 & 5 & 0 & 0 & 0 & 0 & 0 & 0 \\
\hline & qa & & & & & qi & & & & & qu & & & & \\
\hline $1-5$ & 5 & 0 & 0 & 5 & 0 & 0 & 0 & 0 & 5 & 0 & 0 & 0 & 0 & 5 & 0 \\
\hline & ka & & & & & $\mathrm{ki}$ & & & & & $\mathrm{ku}$ & & & & \\
\hline $1-5$ & 0 & 0 & 0 & 5 & 5 & 0 & 0 & \begin{tabular}{|l|}
0 \\
\end{tabular} & 5 & 0 & 0 & 0 & 0 & 5 & 0 \\
\hline & la & & & & & li & & & & & lu & & & & \\
\hline $1-5$ & 0 & 0 & 0 & 5 & 0 & 0 & 0 & 0 & 5 & 0 & 0 & 0 & 0 & 0 & 0 \\
\hline & $\mathrm{ma}$ & & & & & $\mathrm{mi}$ & & & & & $\mathrm{mu}$ & & & & \\
\hline $1-5$ & 0 & 5 & 5 & 5 & 5 & 0 & 0 & 0 & 5 & 0 & 0 & 0 & 0 & 5 & 0 \\
\hline & na & & & & & ni & & & & & $\mathrm{nu}$ & & & & \\
\hline $1-5$ & 5 & 0 & 0 & 5 & 5 & 0 & 0 & 0 & 5 & 0 & 0 & 0 & 0 & 5 & 0 \\
\hline & ha & & & & & hi & & & & & hu & & & & \\
\hline $1-5$ & 0 & 5 & 5 & 5 & 5 & 0 & 0 & 4 & 0 & 0 & 0 & 0 & 0 & 5 & 0 \\
\hline & wa & & & & & wi & & & & & $\mathrm{wu}$ & & & & \\
\hline $1-5$ & 0 & 5 & 0 & 5 & 0 & 0 & 0 & 0 & 5 & 0 & 0 & 0 & 0 & 5 & 0 \\
\hline & ya & & & & & yi & & & & & $\mathrm{yu}$ & & & & \\
\hline $1-5$ & 0 & 0 & 0 & 5 & 0 & 0 & 5 & 0 & 5 & 0 & 0 & 0 & 0 & 5 & 0 \\
\hline $\begin{array}{l}\text { Total scores } \\
\text { per } 5 \text { visits }\end{array}$ & 25 & 45 & 40 & 140 & 60 & 0 & 75 & 79 & 115 & 0 & 0 & 0 & 0 & 110 & 0 \\
\hline $\begin{array}{l}\text { Total scores ofall } \\
\text { visits }\end{array}$ & $68 s$ & & & & & & & & & & & & & & \\
\hline General Mean & 1.6 & & & & & & & & & & & & & & \\
\hline Hypothetical Mean & 137 & & & & & & & & & & & & & & \\
\hline
\end{tabular}

As can be seen in Table 1, the performance of the case was 689 scores out of 2100 scores i.e. $33.8 \%$. The scale was out 5 as mentioned in the rubrics. The score of the patient was examined against that goal (5 scores). Zero scores were given either to the negative or utterly differentproduction. Total scores of everyvisit indicatedeterioration in the first four months ( 25 scores) and also in the last four months (60 scores). The deterioration within the first four months was normal as it follows a stroke and that is what the medical report of the patient indicated to. However, what drew attention is the deterioration in the last four months (16 months after therapy). This can be explained as the patient went through difficult times after his family and relatives left him. The scores of the second four months show that the case started to improve (115 scores). Improvement continued to the end of the third visit (12 months of SLP) when the case got 124 scores. The golden period of improvement was the fourth one (365 scores) where the case started to produce syllables accurately before he 


\section{Ml Macrothink}

deteriorated again andwent back to the point where he started his therapeutic program.

\subsubsection{Syntactic Aspect}

\subsubsection{Nouns}

\subsection{Single Word Proper Nouns}

It is proved by many researchers that aphasic patients lose the ability to name things, notably single and compound proper nouns. However, to in/validate such results; a short test was administered to the case at hand. Like syllables, a set of single proper nouns were given to the case. The role of the case is to repeat the single proper nouns given to him by one of the researchers. The researchers made sure that all target names are known almost by all community members. In addition, some of these single proper names are known to the case. They are either family members or very close friends. Again, the purpose is to prove or disprove results of previous research on the same subject. As usual, the researcher's speech is considered as a model. It was given the total score (5) at the scale of five (5 scores). The case's scores were compared to the researcher's pronunciations based on the above mentioned scale. The following table summarizes the results of ten (10) single proper nouns. Consider:

Table 2. Single proper nouns: Results of five (5) visits.

\begin{tabular}{|c|c|c|c|c|c|c|c|c|c|c|}
\hline $\begin{array}{l}\text { No. of } \\
\text { Visits }\end{array}$ & 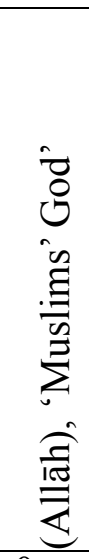 & 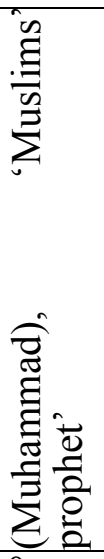 & 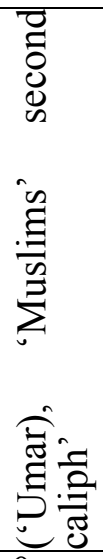 & 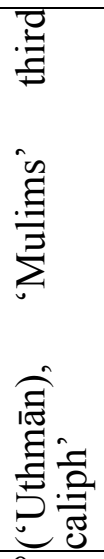 & 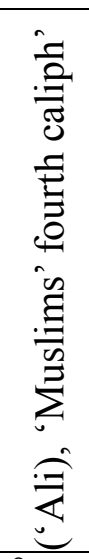 & 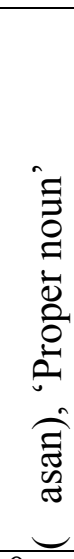 & 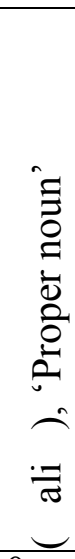 & 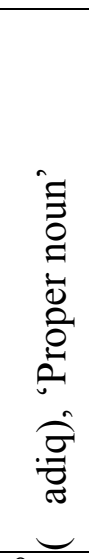 & 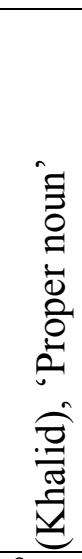 & 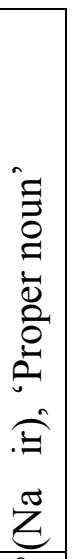 \\
\hline 1 & 0 & 0 & 0 & 0 & 0 & 0 & 0 & 0 & 0 & 0 \\
\hline 2 & 5 & 5 & 5 & 0 & 5 & 5 & 5 & 5 & 5 & 0 \\
\hline 3 & 5 & 5 & 5 & 5 & 5 & 5 & 5 & 5 & 5 & 0 \\
\hline 4 & 5 & 5 & 5 & 5 & 5 & 0 & 5 & 5 & 5 & 5 \\
\hline 5 & 0 & 0 & 0 & 0 & 0 & 0 & 0 & 0 & 0 & 5 \\
\hline Totalscores per 5 visits & 15 & 15 & 15 & 10 & 15 & 10 & 15 & 15 & 15 & $\begin{array}{l}1 \\
0\end{array}$ \\
\hline Total scores ofall visits & \multicolumn{10}{|l|}{135} \\
\hline General Mean & \multicolumn{10}{|l|}{$\begin{array}{l}2.7 \\
27\end{array}$} \\
\hline Hypothetical Mean & \multicolumn{10}{|l|}{27} \\
\hline
\end{tabular}

Based on the results of Table 2, it can be said that the case's performance in producing single proper nouns is improved. However, in comparison to syllables (33.8\%), single proper nouns are better (54\%). Again, the target score was 5 and the same procedure followed with syllables is also used here (silence and/ or wrong answer= zero score). Like syllables, single proper nouns registered high deterioration in the first and last four months. Improvement 


\section{Ml Macrothink}

started from the second four months $90 \%$ and reached its supreme in the third and fourth visits (9th month- 16th month) where the case registered $95 \%$ in the production of single proper nouns.

\subsection{Compound Proper Nouns}

Like single proper nouns, compound nouns were also examined to see whether or not there was a difference in the results between them and those of single proper nouns. Like single proper nouns, compound proper nouns are carefully chosen from the environment of the case. Again, the general aim here is to prove/ disprove the results of prior research on the same topic. Previous studies indicate that Broca's aphasics are impaired more in compound proper nouns than in single proper nouns. However, a total of nine (9) compound nouns were articulated to the case at hand by one of the researchers. The mission of the patient is to repeat them to see to what extent he can produce them properly. Needless to say that researcher's speech is considered as a model. It was given the total score ( 5 scores) at the scale of five ( 5 scores). The case's scores were compared against the researcher's articulation based on the above mentioned scale. The following table summarizes in brief the results of these five visits. Consider:

Table 3. Results of compound proper nouns: Results from the actual utterances of the case.

\begin{tabular}{|c|c|c|c|c|c|c|c|c|c|}
\hline Item & $\begin{array}{l}\frac{\sqrt{10}}{10} \\
\frac{\sqrt{0}}{0} \\
\frac{0}{4}\end{array}$ & 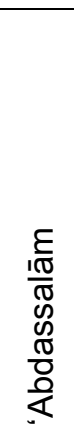 & 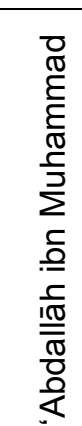 & 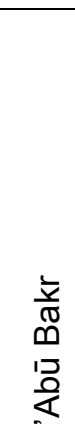 & 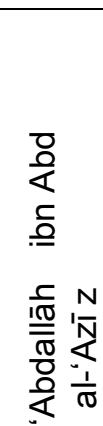 & 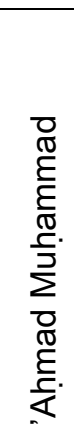 & 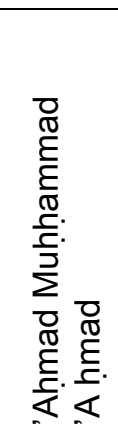 & 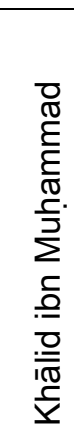 & 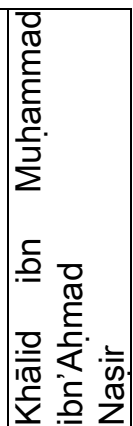 \\
\hline 1 & 0 & 0 & 0 & 0 & 0 & 0 & 0 & 0 & 0 \\
\hline 2 & 5 & 5 & 0 & 5 & 2.5 & 2 & 0 & 0 & 3 \\
\hline 3 & 0 & 5 & 0 & 5 & 5 & 2.5 & 0 & 5 & 0 \\
\hline 4 & 5 & 5 & 0 & 2.5 & 0 & 5 & 0 & 2.5 & 0 \\
\hline 5 & 0 & 0 & 0 & 0 & 0 & 2.5 & 0 & 0 & 0 \\
\hline Totalscores per 5 visit & 10 & 15 & 0 & $\begin{array}{l}12 . \\
5\end{array}$ & 7.5 & 12 & 0 & 7.5 & 3 \\
\hline Total scores of all visits & \multicolumn{9}{|c|}{67.5} \\
\hline General Mean & \multicolumn{9}{|l|}{1.5} \\
\hline Hypothetical Mean & \multicolumn{9}{|c|}{13.5} \\
\hline
\end{tabular}

As mentioned earlier, Table 3 summarizes the performance of the case in compound proper nouns. Needless to say here that the procedure followed in all analyses is the same. Score of the patient is compared to the researcher's articulation based on the goal ( 5 scores). Looking at it statistically, the outlined results of Table 3 indicate general weakness in the performance $(30 \%)$ in comparison to the single proper nouns $(54 \%)$. Like single proper nouns, the first and second four months registered a sever deterioration ( 0 and 2.5 each). The researchers believe that it may be accounted for because of psychological and anthropological reasons explained earlier. Unlike single proper nouns, the second, third and fourth visits showed a little 


\section{MInstitute Macrothink $_{\text {Ins }}$}

improvement $(22.5 \%, 22.5 \%$ and $20 \%$ respectively).

\subsubsection{Verbs}

\subsection{Present Verbs}

Studies show that verbs in present form are damaged in patients with Broca's aphasia. To investigate such results, a short test (set of 20 verbs in the present tense forms in Standard Arabic (SA)) was given to the case who was being asked to repeat them after one of the researchers. To make it easy for the case, the verbs used in the test are some of the most usable ones verbs in SA. Again, researcher's speech is considered as a model. It was given the total score (5) at the scale of five ( 5 scores). The case's scores were compared to the researcher's pronunciations based on the above mentioned scale. The following table shows the case's performance. Consider:

Table 4. The results of the case's performance in present tense verbs forms

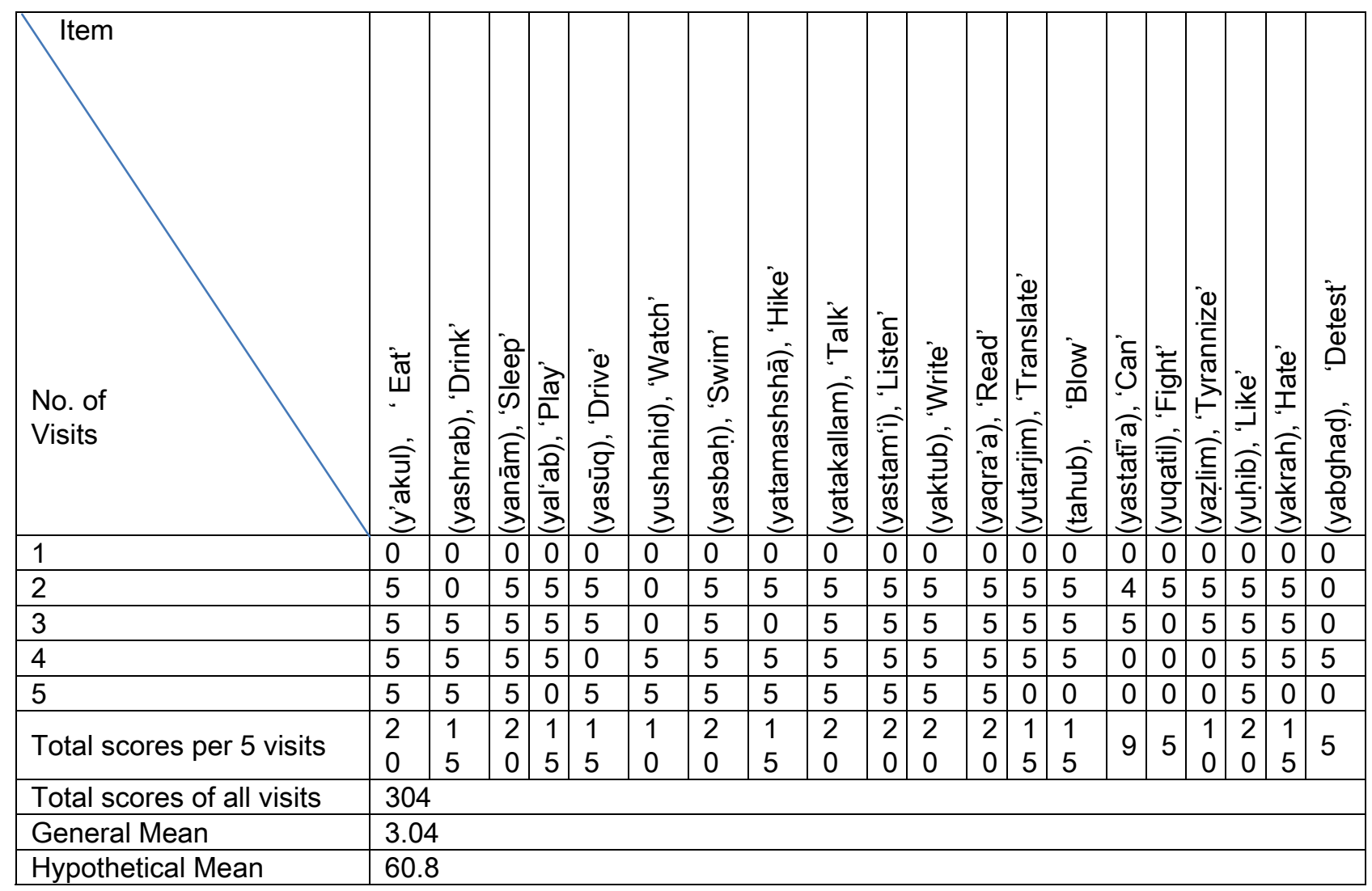

Looking at it from a statistical point of view, Table 4 shows a remarkable progress. This development can be clearly observed starting from the second visit and culminating with the fourth and even the fifth visit. In detail, the second four months registered high change to the best $(79 \%)$ in compare to other phonological and syntactic aspects including syllables and nouns (single proper nouns and compound proper nouns). Likewise, the last four months (17th month- 20th month) is the best period where the case's performance recorded the highest improvement (60\%). This may be accounted for because of the intensive SLP program which was accompanied by the support of case's visitors who kept encouraging him 
that he would be recovered by God wills. However, sessions 3 and 4 showed a similar progress $(80 \%$ each) while session one showed a negative result as usual. All in all, when accounted for his scores in the syntactic aspect, notably present tense verbs and compare them to previous scores of the phonological aspect, it can be said that there is a noticeable improvement in the case's performance and this is clearly seen in the general mean (3.04).

\subsection{Past Verbs}

Like present tense forms, past tense forms were also tested. Outlined results from previous research show that past tense verbs are impaired in patients with Broca's aphasia even more than verbs in present tense form. To examine in which form of the verbs (present or past) the deficit is higher, a set of twenty (20) verbs (most known verbs in SA) were selected by researchers to be given to the case at hand. Again, the case was being asked (during five sessions in 20 months) by one of the researchers to repeat these verbs with him. At the scale of five scores, the case's utterances were compared to those of the researcher who was given the full mark (5 out of 5) to see to what extent his scores (the case) are close to the researcher's. However, the case's results are briefly listed in the table mentioned below. Consider:

Table 5. Past tense verbs: Results of the case's utterances

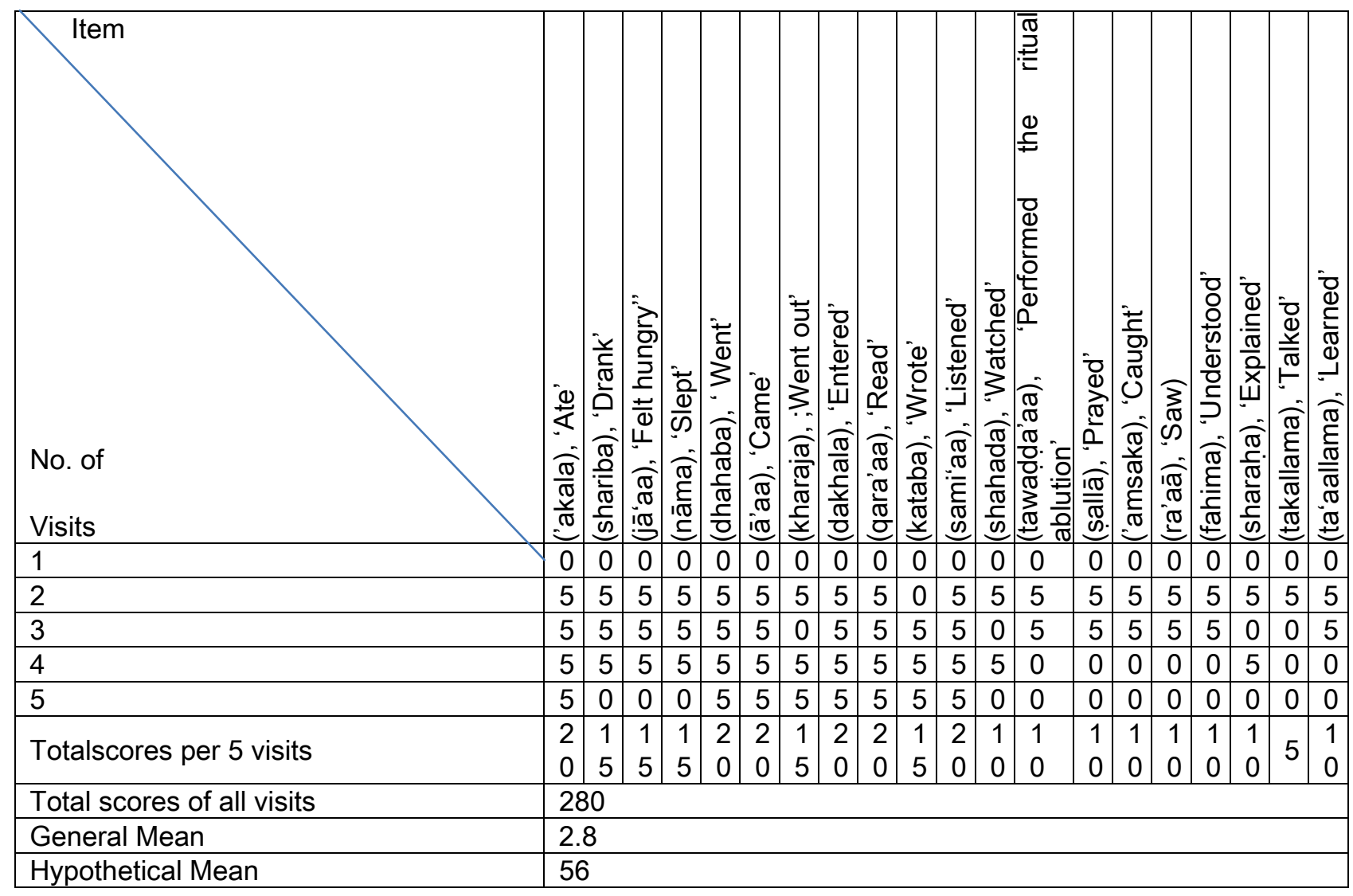

In Table 5 as can be obviously seen, the general performance went backward. For example, last four months registered remarkable deterioration in comparison to the present tense verbs $(60 \%$ vs. $40 \%)$. Also, the fourth session showed a remarkable decline (65\%). Taking into consideration the general mean (2.8), the hypothetical mean (56) and above all the total 


\section{Al Macrothink}

International Journal of English Language Education

ISSN 2325-0887

2013, Vol. 1, No. 2, Special Issue

scores of all visits (280), the general performance of the case in this type of form (past tense) is weaker than that of the present tense form and hypothetical means of the two forms are considered evident evidence (56 and 60.8 respectively).

\subsubsection{Sentences}

\subsection{Affirmative Sentences}

Attempting to dis/prove results of similar studies that sentences of Broca's aphasics are impaired, the researchers administered ten (10) sentences to the case under the question. Like all other items given to the case, sentences are carefully selected by the researchers. These sentences are characterized by simplicity, familiarity and usability. The procedure followed here is the same as the one used for syllables, nouns and verbs. That is, target sentences are uttered by the case who, in turn, repeats them after one of the researchers. Again, the case's performance in producing these sentences was compared to the utterances of the interviewer against the 5 scale. Consider:

Table 6. Case's utterances in affirmative sentence

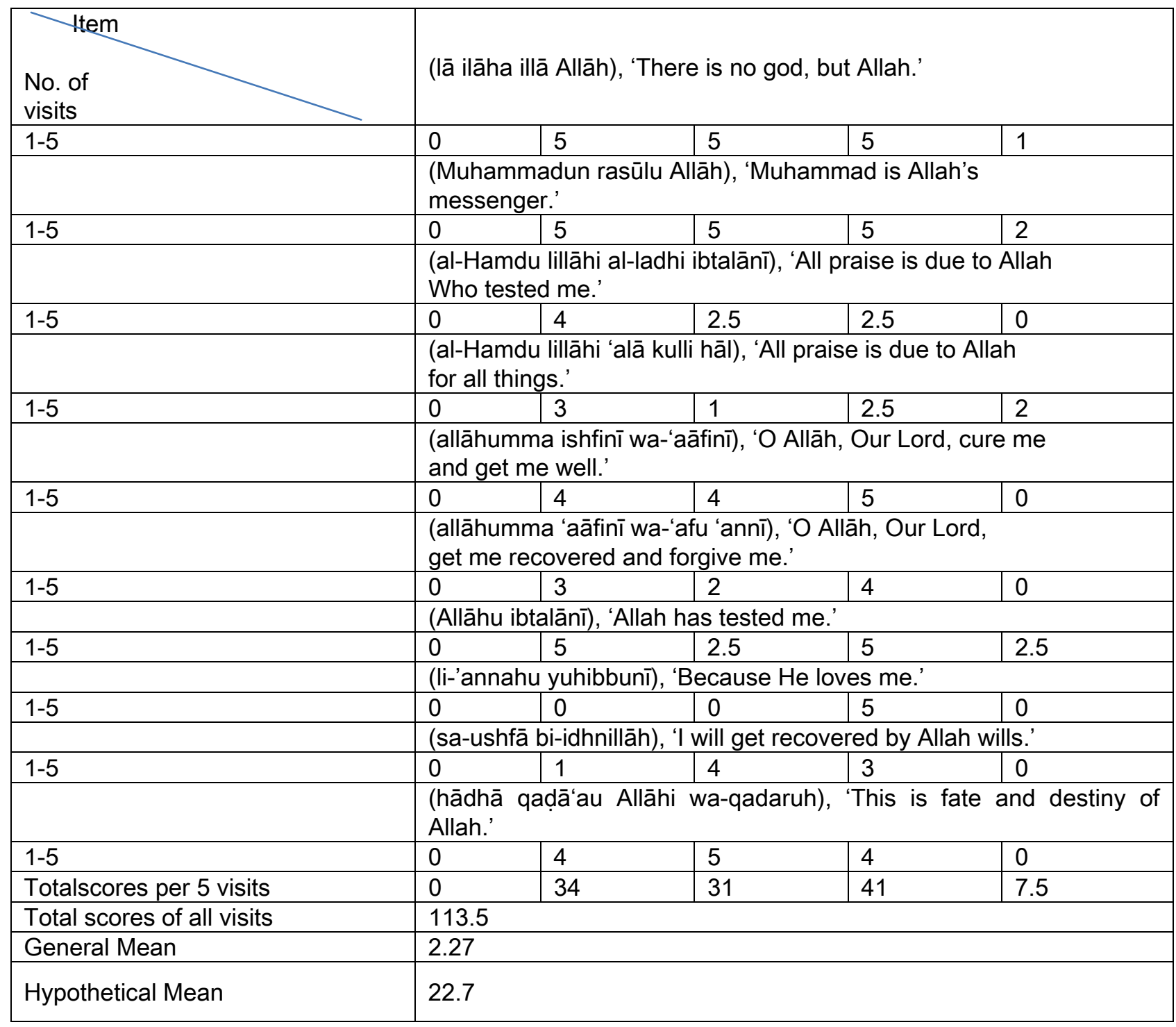




\section{Macrothink}

Again, Table 6 is another random sample that proves the validity and reliability of the research. Results are, generally speaking, similar to each other with slightly differences. The first and last four months registered the lowest scores as usual ( 0 and 7.5 respectively). It is true that improvement fell back in the third visit (9th month-12th month) when compared to the progress of the second four months, yet it was resumed in the fourth visit (13th month16th month) where it registered 37 scores. Taken together and with reference to the previous scores, it can be said that the case's performance in affirmative sentence $\mathrm{s}$ is below the level $(43 \%)$.

\subsection{Active- passive Sentences}

As a language aspect, sentences were also tested by the researchers who wanted to investigate to what extent results of previous studies are precise. However, it is proved by some researchers that in aphasic patients, active sentences are impaired more than passive sentence. In order to examine such outcomes, the case in hand has been given twenty famous sentences (ten active voice sentence and ten passive voice sentences). The purpose was to compare the performance of the case in producing the two groups to see in which group exactly, deficit is worse. Scores as usual are compared to one of the researcher's ( 5 scores) at the scale of 5 scores. Compare:

Table 7. The case's performance in both active and passive voice sentence: Comparison

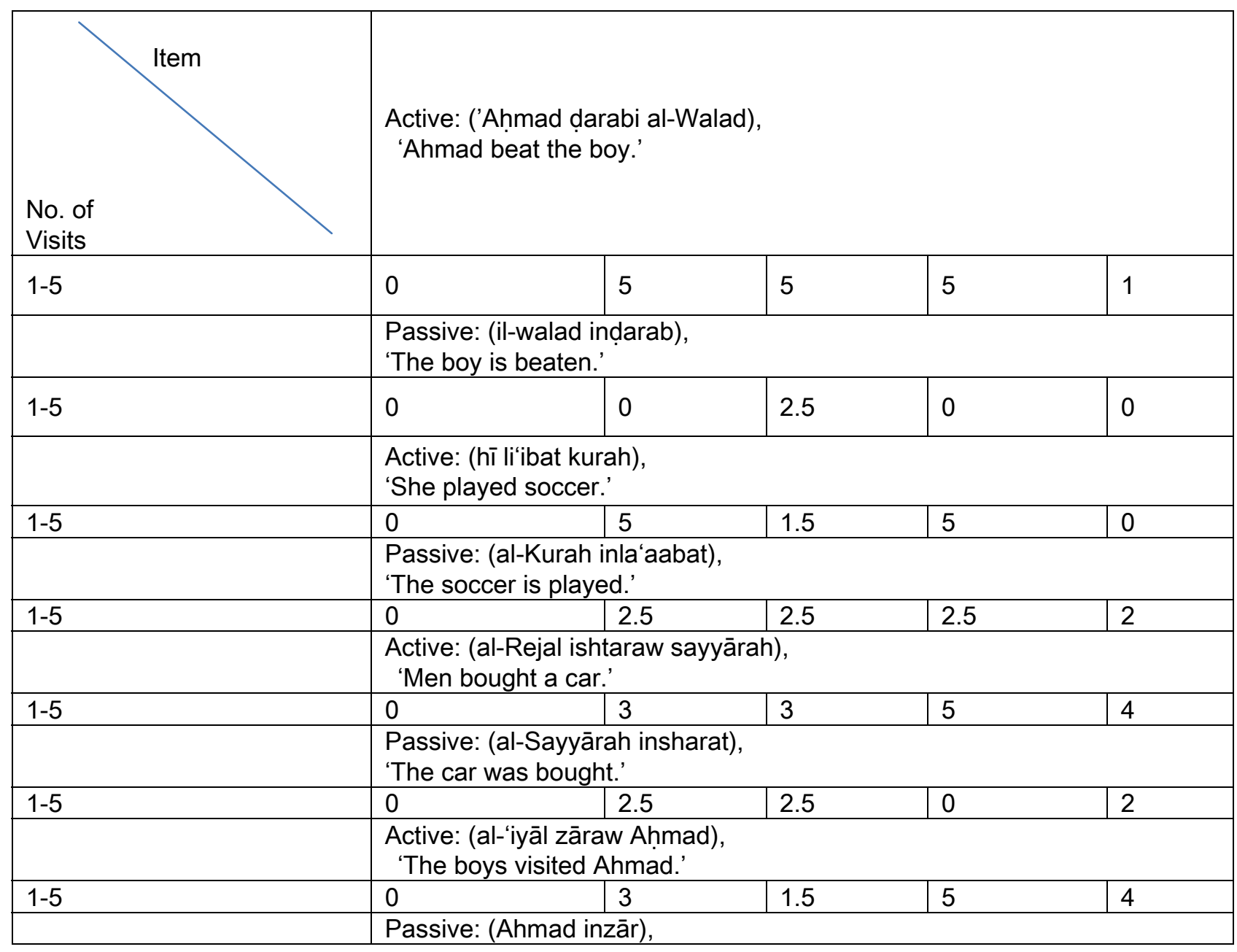




\section{Macrothink}

International Journal of English Language Education

ISSN 2325-0887

2013, Vol. 1, No. 2, Special Issue

\begin{tabular}{|c|c|c|c|c|c|}
\hline & \multicolumn{5}{|c|}{ 'Ahmad was visited.' } \\
\hline \multirow[t]{2}{*}{$1-5$} & 0 & 2.5 & 2.5 & 4 & 0 \\
\hline & \multicolumn{5}{|c|}{$\begin{array}{l}\text { Active: (al-Bazarīn bitishrab al-'ilaj), } \\
\text { 'Boys are taking the medicine.' }\end{array}$} \\
\hline \multirow[t]{2}{*}{$1-5$} & 0 & 3 & 2 & 5 & 5 \\
\hline & \multicolumn{5}{|c|}{$\begin{array}{l}\text { Passive: (al-'ilaj bi-yinsharib), } \\
\text { 'The medicine is being taken.' }\end{array}$} \\
\hline \multirow[t]{2}{*}{$1-5$} & 0 & 2.5 & 2.5 & 2 & 2 \\
\hline & \multicolumn{5}{|c|}{$\begin{array}{l}\text { Active: (al-Nās bi-yishtarū montajāt 'abil al-Shar al-Jāy), } \\
\text { 'People are going to buy Apple's products next month.' }\end{array}$} \\
\hline \multirow[t]{2}{*}{$1-5$} & 0 & 0 & 1 & 2 & 2 \\
\hline & \multicolumn{5}{|c|}{$\begin{array}{l}\text { Passive: (montajāt 'abil bi-tinsharī al-Shahr al-Jāy), } \\
\text { 'Apple's products are going to be bought next month.' }\end{array}$} \\
\hline \multirow[t]{2}{*}{$1-5$} & 0 & 0 & 0 & 0 & 0 \\
\hline & \multicolumn{5}{|c|}{$\begin{array}{l}\text { Active: (al-Tullāb Jāwabaw 'alā al-'Asi'lah al-Sa'abah), } \\
\text { 'Students answered difficult questions.' }\end{array}$} \\
\hline \multirow[t]{2}{*}{$1-5$} & 0 & 0 & 1.5 & 3 & 3 \\
\hline & \multicolumn{5}{|c|}{$\begin{array}{l}\text { Passive: (al-'Asi'lah al-Sa'abah injawab 'alihā), } \\
\text { 'Difficult questions were answered.' }\end{array}$} \\
\hline \multirow[t]{2}{*}{$1-5$} & 0 & 0 & 2.5 & 2.5 & 1 \\
\hline & \multicolumn{5}{|c|}{$\begin{array}{l}\text { Active: (al-'Awqaf rah tihdim al-Masjid al-Qadim), } \\
\text { 'Ministry of endowment will destroy old mosque.' }\end{array}$} \\
\hline \multirow[t]{2}{*}{$1-5$} & 0 & 2 & 1 & 3 & 0 \\
\hline & \multicolumn{5}{|c|}{$\begin{array}{l}\text { Passive: (al-Masjid al-Qadīm bi-yinhidim), } \\
\text { 'Old mosque will be destroyed.' }\end{array}$} \\
\hline \multirow[t]{2}{*}{$1-5$} & 0 & 0 & 0 & 2 & 0 \\
\hline & \multicolumn{5}{|c|}{$\begin{array}{l}\text { Active: (al-Quwwat al-Si'udiyah bi-Tidhar al-Hūthiyīn inshāllāh inshāllāh), } \\
\text { 'Allah had willing, Saudi military force is going to drive away Hūthīs.' }\end{array}$} \\
\hline \multirow[t]{2}{*}{$1-5$} & 0 & 2.5 & 1 & 2 & 1 \\
\hline & \multicolumn{5}{|c|}{$\begin{array}{l}\text { Passive: (al-Huthiyīn bi-yindiḥrūn inshāllāh), } \\
\text { 'Allah da willing, Hūthis are going to be driven away.' }\end{array}$} \\
\hline \multirow[t]{2}{*}{$1-5$} & 0 & 0 & 0 & 1 & 1 \\
\hline & \multicolumn{5}{|c|}{$\begin{array}{l}\text { Active: (al-Muntakhab al-Si'udī bi-yihzim al-Muntakhab } \\
\text { al- 'Umañ̄ fil mubārāh } \\
\text { al-Jāyah), 'Saudi team will defeat Oman's team next match.' }\end{array}$} \\
\hline \multirow[t]{2}{*}{$1-5$} & 0 & 2 & 0 & 0 & 1 \\
\hline & \multicolumn{5}{|c|}{$\begin{array}{l}\text { Passive: (al-Muntakhab al- 'Umanī bi-Yinhizim), } \\
\text { 'Omani team will be defeated.' }\end{array}$} \\
\hline $1-5$ & 0 & 2 & 0 & 0 & 1 \\
\hline $\begin{array}{l}\text { Total scores of active voice } \\
\text { sentences per } 5 \text { visits }\end{array}$ & 0 & 25.5 & 17.5 & 35 & 21 \\
\hline $\begin{array}{l}\text { Total score of all active voice } \\
\text { sentences in all visits }\end{array}$ & 99 & & & & \\
\hline General mean of active voice & 1.9 & & & & \\
\hline
\end{tabular}




\begin{tabular}{|l|l|l|l|l|l|}
\hline sentences & \multicolumn{5}{|l|}{} \\
\hline $\begin{array}{l}\text { Hypothetical mean of active } \\
\text { voice sentences }\end{array}$ & 19.8 & 12 & 15 & 14 & 9 \\
\hline $\begin{array}{l}\text { Total scores of passive voice } \\
\text { sentences per 5 visits }\end{array}$ & 0 & 50 & & \\
\hline $\begin{array}{l}\text { Total scores of passive voice } \\
\text { sentences in all visits }\end{array}$ & 1 & 10 & & \\
\hline $\begin{array}{l}\text { General mean of passive } \\
\text { voice sentences }\end{array}$ & 149 & 1.49 \\
\hline Hypothetical mean & $\begin{array}{l}\text { Total scores of both passive } \\
\text { active and pentences active } \\
\text { seneral mean of both active } \\
\text { and passivesentences }\end{array}$ & 29.8 \\
\hline $\begin{array}{l}\text { Hypothetical mean of both } \\
\text { active and passive } \\
\text { voice sentences }\end{array}$ &
\end{tabular}

In light of the scores in Table 7, it is felt that a distinction ought to be made between the performance of the casein active and passive voice sentences. General overview on the scores per 5 visits show that the case's performance in active voice sentence is more than that of passive voice. However, both types (active and passive voice sentences) registered low scores in the first four months (zero each) but not in the last four months. In the months from October 2011 to January 2012 the case's performance was better in active voice sentences than in passive voice ( 21 and 9 respectively). While the third visit registered a similar progress in both active and passive sentences (17 and 15), the second and fourth showed the opposite as scores in active sentences were almost double than those of the passive (25.5 and 12), and (35and 14). Overall, the picture becomes clear in view of the total scores of all visits where it registered 99 scores for active against 50 scores for the passive i.e. $36 \%$ vs. $20 \%$. To sum up what has been discussed earlier, it can be said that performance of the patient under the question in active voice sentences is better than that of the passive voice sentences and the general two means are the best evidence (1.98 vs.1).

\subsection{Production, Naming and Selection, and Sign Language}

\subsubsection{Production \& Selection of the Lexical Items}

\subsubsection{Production of the Lexical Items}

Outlined results of studies undertaken before show that Broca's aphasics suffer from word production. Researchers believe, however, that in order to prove or disprove such results, a short test must be administered to examine the ability of the case to articulate lexical items. Like other short tests, this test consists of ten (10) words that are written by the researchers. The drill determines that the case name the words written. Researchers intentionally chose words that are commonly used almost by all society members. The case's scores were examined against the researcher's at the scale 5 scores. Results of the case's performance can be clearly explained in light of the following table. Consider: 


\section{MlMacrothink}

Table 8. Lexical Production Test: Results of the case's performance

\begin{tabular}{|c|c|c|c|c|c|}
\hline \multirow{2}{*}{$\frac{\text { No. of Visits }}{1-5}$} & \multicolumn{5}{|c|}{ (kurah), 'Ball' } \\
\hline & 0 & 0 & 0 & 5 & 0 \\
\hline & \multicolumn{5}{|c|}{ (tilfiziūn), 'Television' } \\
\hline $1-5$ & 0 & 5 & 0 & 5 & 0 \\
\hline & \multicolumn{5}{|c|}{ (fil), 'Elephant' } \\
\hline $1-5$ & 0 & 5 & 0 & 5 & 0 \\
\hline & \multicolumn{5}{|c|}{ (tuffāḥah), 'Apple' } \\
\hline $1-5$ & 0 & 0 & 0 & 0 & 0 \\
\hline & \multicolumn{5}{|c|}{ (rajul), 'Man' } \\
\hline $1-5$ & 0 & 0 & 0 & 0 & 0 \\
\hline & \multicolumn{5}{|c|}{ (thamar), 'Fruit(s)' } \\
\hline $1-5$ & 0 & 0 & 0 & 0 & 0 \\
\hline & \multicolumn{5}{|c|}{ (thawb), 'Traditional Arab dress' } \\
\hline $1-5$ & 0 & 0 & 0 & 0 & 0 \\
\hline & \multicolumn{5}{|c|}{ (kumbiūtar), ' Computer' } \\
\hline $1-5$ & 0 & 0 & 0 & 0 & 0 \\
\hline & \multicolumn{5}{|c|}{ (jawwāl), 'Cellphone' } \\
\hline $1-5$ & 0 & 0 & 0 & 0 & 0 \\
\hline & \multicolumn{5}{|c|}{ (ibil), 'Camels' } \\
\hline $1-5$ & 0 & 0 & 0 & 5 & 0 \\
\hline Totalscores per 5 visits & 0 & 10 & 0 & 20 & 0 \\
\hline Total scores of all visits & \multicolumn{5}{|c|}{30} \\
\hline General Mean & \multirow{2}{*}{\multicolumn{5}{|c|}{0.6}} \\
\hline Hypothetical Mean & \multicolumn{4}{|l|}{6} & \\
\hline
\end{tabular}

Evidently, in Table 8, the case shows obvious deterioration in the third and fifth visits (9th month-12th month and 13th month-16th month). Of course, the deterioration of the first four months is normal as it is almost permanent in most visits due to the fact that the patient has just received a stroke. What was not expected is the third visit (9th month -12th month) where the case's performance is supposed to be improved. The hypothetical mean of the lexical production is the lowest ever (6). Overall, it can be said that the performance of the case in producing lexical items is very weak and the general mean is the evidence (0.6).

\subsubsection{Selection of the Lexical Items}

To in/validate the results that Broca's aphasics face problems related to word selection, researchers decided to administer another short test through which word selection impairment can be examined. Like most of the tests administered earlier, the number of the target words was ten (10). They were presented in terms of multiple choice forms and each choice consists of three words: Target word plus two more words (distractors). All choices were randomly designed. The test was undertaken as follows: One of the researchers gives the case the target word and then asks him to select it from among the multiple choices. Again, the point is to see to what extent this aspect is impaired in comparison to the findings of other studies. Additionally, the researchers wanted to know in which of the two aspects (lexical production and lexical selection) the case is affected more. Of course, the same evaluation that has been 


\section{Macrothink}

International Journal of English Language Education ISSN 2325-0887 2013, Vol. 1, No. 2, Special Issue

followed with the previous tests is also used here. Results of the case's performance are compared to the model (the researcher's) at the scale of 5 scores. The following table summarizes the case's performance.

Table 9. Results of the case's Lexical Selection Test

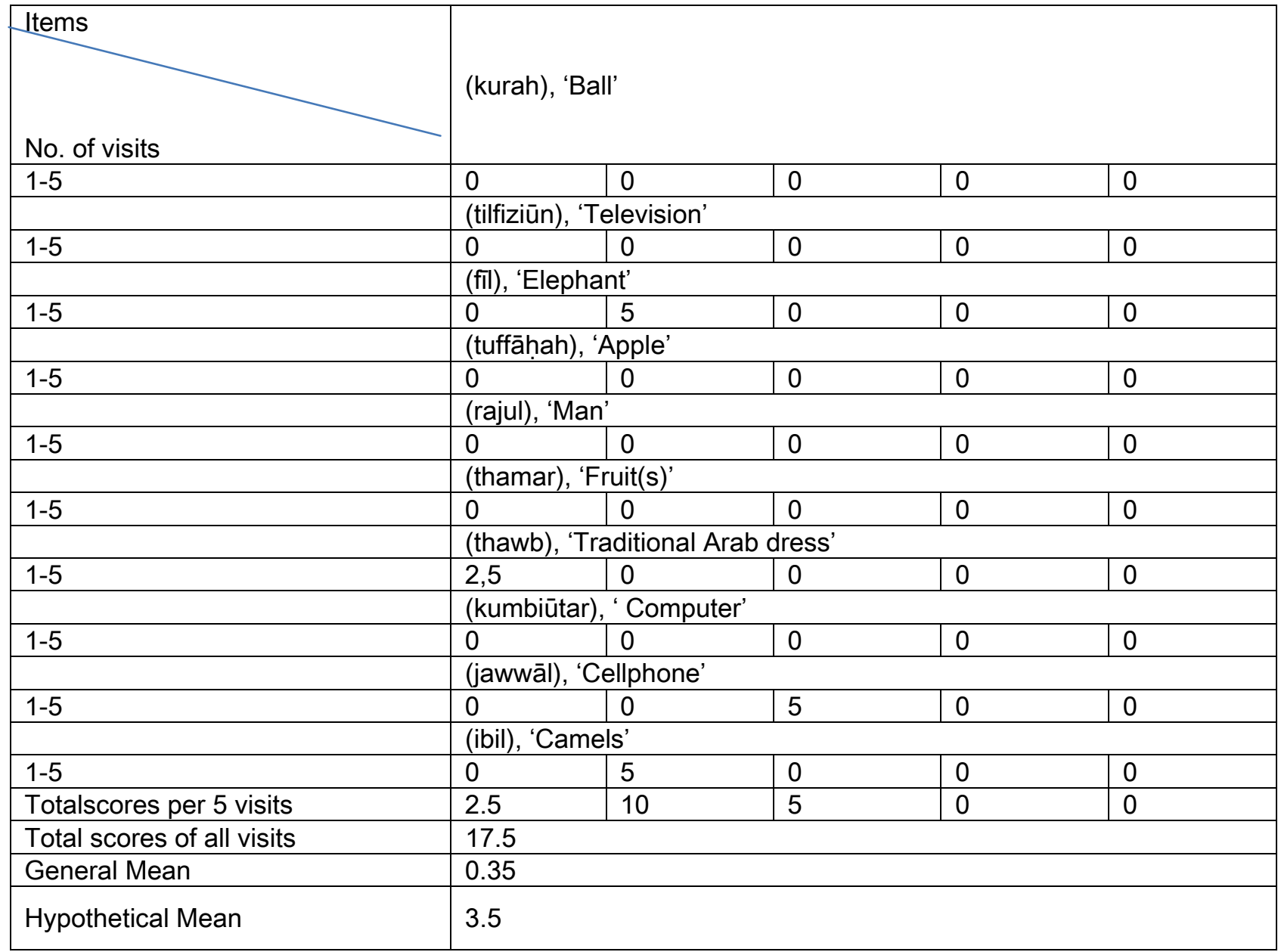

In comparison to results mentioned in Table 8, scores of Table 9 are worse. In detail, the performance of the case in the fourth and fifth visits (13th month- 20th month) is zero. This means that deterioration increased as time goes. In fact this deterioration in lexical selection is remarkable and results of the first twelve months prove that. Again, in comparison to the outcomes of lexical production, results of lexical selection are worse. Total scores of all visits and those of the general and hypothetical means prove that. The general performance of the case in lexical selection is very weak (35\%).

\subsubsection{Naming \& Selection of Pictures}

\subsubsection{Picture Naming}

To ensure the validity, reliability, accountability and credibility of the study, the researchers tried their best to make the tests comprehensive so to cover all language aspects. For that matter, one of the objectives they take into consideration is to test all results and hypotheses of other researchers who have undertaken studies on similar cases. Since it is found that 


\section{Ml Macrothink}

International Journal of English Language Education

ISSN 2325-0887

2013, Vol. 1, No. 2, Special Issue

picture naming is one of the language deficits that Broca's aphasics suffer from, there was a necessity to tackle this issue seriously. For that matter, another short test similar to the ones mentioned earlier was administered. This time, the target was not a lexical item, but a picture. The most famous persons and places in the case's community were individually presented to him. He was being asked by one of the researchers to name these pictures from among a multiple choices. Again, the same procedure of assessment was followed in this test also (Comparing the scores of the case to the right answer at the scale of 5 scores to see whether or not his answer is right). Consider:

Table 10. Picture naming test: Results of the case's performance.

\begin{tabular}{|c|c|c|c|c|c|}
\hline $\begin{array}{l}\text { Target Picture } \\
\text { No. of visits } \\
\end{array}$ & \multicolumn{5}{|c|}{ (al-Ka'bah), 'The Kaaba' } \\
\hline \multirow{2}{*}{$1-5$} & 7 & & & & \\
\hline & \multicolumn{5}{|c|}{ (al-Malik 'Abdallāh), 'King Abdullah' } \\
\hline \multirow[t]{2}{*}{$1-5$} & 0 & 0 & 2.5 & 0 & 0 \\
\hline & \multicolumn{5}{|c|}{ (Bahr), 'Sea' } \\
\hline \multirow[t]{2}{*}{$1-5$} & 0 & 0 & 0 & 0 & 0 \\
\hline & \multicolumn{5}{|c|}{ (al-'Amīr Sultān), 'Prince Sultan' } \\
\hline \multirow[t]{2}{*}{$1-5$} & 0 & 0 & 0 & 0 & 0 \\
\hline & \multicolumn{5}{|c|}{ (ibn Șālih), 'The case's son' } \\
\hline \multirow[t]{2}{*}{$1-5$} & 0 & 0 & 0 & 0 & 0 \\
\hline & \multicolumn{5}{|c|}{ (șūratak), 'Your (The case) personal photo)' } \\
\hline \multirow[t]{2}{*}{$1-5$} & 0 & 0 & 0 & 0 & 0 \\
\hline & \multicolumn{5}{|c|}{ (Sayyārah), 'Car' } \\
\hline \multirow[t]{2}{*}{$1-5$} & 0 & 0 & 0 & 0 & 0 \\
\hline & \multicolumn{5}{|c|}{ (bintak) 'Your (The case) daughter' } \\
\hline \multirow[t]{2}{*}{$1-5$} & 0 & 0 & 0 & 0 & 0 \\
\hline & \multicolumn{5}{|c|}{ (dab), 'Uromastyx aegyptius dabb'= 'A fat-tailed lizard } \\
\hline \multirow[t]{2}{*}{$1-5$} & 0 & 0 & 0 & 5 & 0 \\
\hline & \multicolumn{5}{|c|}{ (malik al-Bahrayn), 'Bahrain King' } \\
\hline $1-5$ & 0 & 0 & 0 & 0 & 0 \\
\hline Totalscores per 5 visits & 0 & 0 & 2.5 & 5 & 0 \\
\hline Total scores of all visits & \multicolumn{5}{|c|}{7.5} \\
\hline General Mean & \multicolumn{5}{|c|}{0.15} \\
\hline Hypothetical Mean & \multicolumn{5}{|c|}{1.5} \\
\hline
\end{tabular}

Table 10 reveals that deterioration in picture selection reached its zenith. Evidently, the results of the third and fourth visits are similar to those of lexical selection, but the fact is that these scores are worse. Put in other way, in comparison to his performance in lexical production, the case's performance in picture naming is worse $(15 \%)$.

\subsubsection{Picture Selection}

Picture selection is also found to be another deficit that Broca's aphasics suffer from. The following short test is expected to either support results of previous research or contradict with them. Like many other tests administered in this study, the following test consists of 10 target items (pictures). Each item consists of three pictures (a target picture plus two distractors). They were all given to the case to select the target one. The challenge here is to 


\section{1l Macrothink}

International Journal of English Language Education

ISSN 2325-0887

2013, Vol. 1, No. 2, Special Issue

select the right picture that the researcher has already asked him about in the previous exercise. In clearer terms, the interviewer first asks the case to name a picture, then put it in multiple choices and ask him again to choose the same picture that he has already seen. Again, pictures belong to the environment of the case to enhance him to articulate and select. Scores were compared to the right answer at the scale of 5 . The following table summarizes the performance of the case. Consider:

Table 11. Picture selection test: Results of the case's performance

\begin{tabular}{|c|c|c|c|c|c|}
\hline \multirow{2}{*}{$\begin{array}{l}\text { No. of visits } \\
1-5\end{array}$} & \multicolumn{5}{|c|}{ (al-Ka'abah), 'The Kaaba' } \\
\hline & 0 & 0 & 0 & 0 & 0 \\
\hline & \multicolumn{5}{|c|}{ (al-Malik ‘Abdallāh), 'King Abdullah' } \\
\hline $1-5$ & 0 & 0 & 0 & 0 & 0 \\
\hline & \multicolumn{5}{|c|}{ (baḥr), 'Sea' } \\
\hline $1-5$ & 0 & 0 & 0 & 0 & 0 \\
\hline & \multicolumn{5}{|c|}{ (al-'Amīr Șultān), 'Prince Sultan' } \\
\hline $1-5$ & 0 & 0 & 0 & 0 & 0 \\
\hline & \multicolumn{5}{|c|}{ (ibn Șāliḥ), 'The case's son' } \\
\hline $1-5$ & 0 & 0 & 0 & 0 & 0 \\
\hline & \multicolumn{5}{|c|}{ (șūratak), 'Your (The case) personal photo)' } \\
\hline $1-5$ & 0 & 5 & 0 & 0 & 0 \\
\hline & \multicolumn{5}{|c|}{ (sayyārah), ‘Car' } \\
\hline $1-5$ & 0 & 0 & 0 & 0 & 0 \\
\hline & \multicolumn{5}{|c|}{\begin{tabular}{|l} 
(bintak) 'Your (The case) daughter' \\
\end{tabular}} \\
\hline $1-5$ & 5 & 5 & 0 & 0 & 0 \\
\hline & \multicolumn{5}{|c|}{ (dab), 'Uromastyx aegyptius dabb'= 'A fat-tailed lizard' } \\
\hline $1-5$ & 0 & 0 & 0 & 0 & 0 \\
\hline & \multicolumn{5}{|c|}{ (malik al-Bahrayn), 'Bahrain King' } \\
\hline $1-5$ & 0 & 0 & 0 & 0 & 0 \\
\hline Totalscores per 5 visits & 5 & 10 & 0 & 0 & 0 \\
\hline Total scores of all visits & \multicolumn{5}{|c|}{15} \\
\hline General Mean & \multicolumn{5}{|c|}{0.3} \\
\hline Hypothetical Mean & \multicolumn{5}{|l|}{3} \\
\hline
\end{tabular}

Table 11 reveals another type of deterioration in picture selection. This time, the deterioration includes the third and fourth visits (9th month- 16th month) unlike many other aspects where this period represents the golden period of improvement and progress. However, deterioration in picture selection is not worse than that of picture naming. It might be different due to the fact that the patient could select the right picture (his daughter) from a multiple choice in the first four months after the stroke. Based on the total scores of all visits, the general and the hypothetical means, it can be said that the case's performance in picture selection is weak $(30 \%)$.

\subsubsection{Sign Language}

Almost in all case's answers, the interviewer was asking him to use his hand to point to the answer (the choice he was asked to make/ select). However, the case responded to such instructions, but not all the time. The researchers believe that without these instructions, the 
case would not use his hand to answer. Concerning other paralinguistic elements including the facial expressions, gestures, body actions, nodes, etc., the case was using them to indicate either recognition of a name or an identification of a picture. Seemingly, intra linguistic elements aretheonly language left for him through which he expresses his feelings, sensations, emotions, etc. For example, he was using eye gazing to point to a person or a thing he wants to drawattention to others. Using tears as a means of expressing his anger or sadness was an effective means of expressing what he wants to say or do.

\section{Data Interpretation and Discussion}

\subsection{Conclusion}

Right after the stroke, the family played a negative role which hindered the case at hand from any progress in his pathological program. According to the medical records, the case's LIFG is impaired; that is why, sentence processing is impaired. This is strong evidence that LIFG plays a pivotal role in BA. This result supports the study of Ghislaine et al., (2006) who emphasizes the significant role played by LIFG as it helps in re-analyzing facial misinterpretation. As a result, the patient failed many times to interpret the interviewer's explanations that were expected to help him match the right sentence he has heard with the right picture he was asked to match the sentence with. Again, such outcomes confirm the results of Eiling et al., (2008) who proved that LIFG has a vital role concerning the processes of matching. It is almost agreed by all neurolinguistics that that LIFG is the responsible for language production in BA. It means that the role of LIFG is essential and in a case if it is impaired (like what happened with the case at hand), the result is that the person becomes aphasic and his/her language production is partially or completely deteriorated. That is what happened actually to the case under the question and that is what his medical records and the recordings indicated to. Undoubtedly, the outcomes of this study confirm many other results by different researchers (Musso et al., 2011; Dronkers et al., 2011; Tyler et al., 2011).

In light of the patient's responses to short tests administered for him, it can be said that most language aspects are impaired. This diversity of responses provides the researchers of the current study with a rich source of potential background about how language is affected if BA is damaged. Interdisciplinary speaking, the integrity in language aspects supports the holistic approach hypothesis (Tsapkini et al., 2008). However, theoretical evidence can at best provide only a base or a core of the present study. They should be supported by practical evidence from the actual utterances of the case at hand. Again, in view of the case's utterances analyzed in the previous section, it can be said that he failed to produce certain sounds (syllables). Such result was discussed before by Fiez (2011)'s study.In comparison to his performance in compound nouns, the case's performance in single nouns found to be better which asserts the conclusion of Ter Kerus et al., (2002)'sstudy.

The case also failed to produce the verbs, notably those of the past. Theseresults state firmly the results of some studies which proved that in Broca's aphasics, verbs are severely impaired (Bastiaanse \& Thompson; 2003; Bastiaanse \& Van Zonneveld, 2004; Barber et al., 2005). The study of Dickey\& Thompson (2007) and that of Venkatajaja et al., (2009)found thatsyntactic and morphological impairment (morphosyntactic deficits) are found to be 
correlated and are impaired at the same time in Broca's aphasics. In addition to the above mentioned results, the current study proved that phonological aspect is also impaired. Concerning the syntactic aspect, the present study found that verbs in Broca's aphasics are impaired more than nounswhich confirm the results of Cappelletti et al. (2006) and those of Jonkers \& de Bruin's (2009).

The case's continuous failure in producing correct sentencesin the five sessions can be explained as a result to impairment in his syntactic and pragmatic processing. Obviously, the case's sentences lack the hierarchal structure which is involved in sentence processes. Such findings support those of many other researchers (Nakano\& Blumstein, 2004; Wassennar et al., 2004; Ragalsky, 2008). They also confirm the assumption of Dinks \& Carroll (2005) who emphasize on the importance of the role of the tense in Broca's aphasia. Comparing his response to active and passive sentences, the case's response was partially positive to the former, but completely negative to the latter. These results show the results of the study of Bastiaanse \& Zonneveld (2005) are definitely true. They also agree with the Trace Deletion Hypothesis (TDH) which contends that aphasics perform active voice sentences than they do to passive sentences. Additionally, the results add evidence to Caramazza's et al.'s (2005) study that has proved the hypothesis.

The researchers of the current study concluded that the case's silence in the first session is "normal" due to a stroke. The situation of the case, according to the researchers is similar to that of Clarke, the case of Parr and et al., (2003) who was unable to say any word including his name. Silence, Psychoneurolinguistically speaking, is normal right after the stroke. However, this silence is not justified after pathological and therapeutic programstook place. To date, it is deterioration that needs to be treated in light of psychological and anthropological efforts. These include the role of the family, relatives, society, etc. These findings affirm the results of Kauhanan et al.'s (2000) and those of Simmons (2001) and Laska et al., (2001).

Results of the present study also show that the patient is suffering from severe anomia and this is a strong indication that his problem is that of expressive aphasia, because anomia is considered as one of its symptoms. For example, he failed to name words given to him by the interviewer. The failure continued when he could not make the right choice from among the multiple choices he has given and also when he failed to name the picture and match it with the suitable sentence given to him. These outcomes assert many studies that came up to the same conclusions (Singla et al., 2007; Bendy et al., 2007; Wassenaar et al., 2007; Heim et al., 2011a; Heim et al., 2011b; Semenza et al., 2011).

All in all, when accounting for the performance of the case in all five visits, it can be said that that picture selection, lexical production, picture naming and lexical selection registered the highest scores of impairments $(0.3,0.6,0.15$ and 0.35 respectively). On the other hand, passive voice, syllables, compound proper nouns, active voice sentences, single proper nouns, past tense verbs, affirmative sentence $\mathrm{s}$, and present tense verbs recorded lower scores of impairments $(1,1.6,1.5,1.98,2.7,2.8,2.27$ and 3.04). The following figure summarizes these results. Consider: 


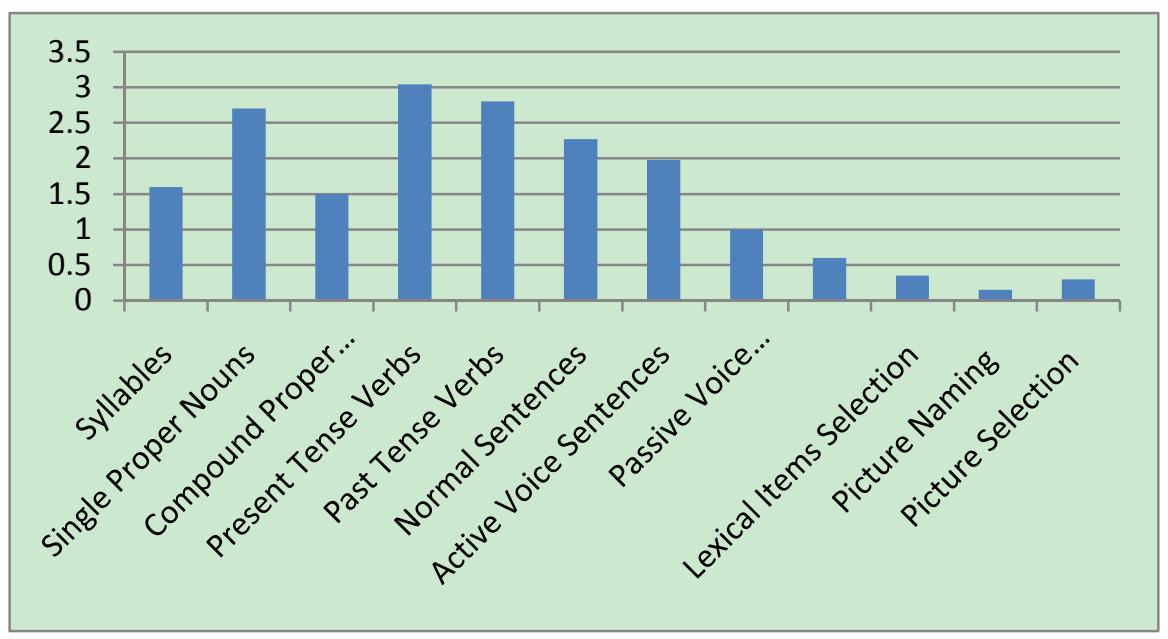

Figure 1. Percentages of impairmentsand their distributions

As can be clearly seen, Figure 1 shows that the case registered the highest progress in present tense verbs, but lowest in picture naming. Nor must we forget the speech of the case which was associated by sign language. It is seen that he was making use of facial expressions every now and then. For example, he was moving his eye and hand to point to the words and the same thing applies to the pictures. These results support the conclusion of Skipper et al., (2007).Such behavior forced the researchers to sign their language sometimes as it helped the case understand what they want him to do. Such procedure was used before and proved its effect (Skipper et al., 2007). Finally, outline results also show the significance of the psychological factors and its role, mainly during the process of the rehabilitation program as it determines to what extent the patient responds to this or that therapeutic treatment.

\subsection{Recommendations}

Based on the above mentioned results and conclusions, the researchers recommend that heavy smokers should stop smoking. Smokers also should be warned that smoking is, scientifically speaking, a main cause for strokes. Smoking consists of different toxic substances (fatal weapons) that bring death to our body. In other words, smoking smokes us. It makes usprone to be aphasics and the case under the question is a real example. Old people are strongly advised to do some unusual aerobics, practices, exercises, etc. to avoid receiving stroke. They should keep themselves healthy by practicing sports and exercise. These include walking backwards, moving the left hand, and / or using it to perform such things that we never do, jumping on the left leg, etc. One of the benefits of doing such exercises is that the cells in the brain that are responsible for these parts move. Neurolinguistically speaking, if these cells remain without any activities, the brain becomes a good environment for sudden cerebrovascular.

Listening to Holy Qur'an is also recommended because it consists of tens of examples on segmental and supra-segmental features that are proved to be helpful (Melodic Intonation Therapy), notably after stroke (Sārkāmū et al., 2008; UHIR, 2008). Singing famous songs and reciting poems, notably national ones are also recommended. They are found to be useful for aphasics who prefer more to sing for example than to listen to songs (Schlug et al., 2008). 
Intensive Linguistic Specific Treatment (LSI) is also recommended. These include pathological and therapeutic exercises like Propranolol therapeutic program that helps overcome anomia in aphasic patients. Nor must we forget software programs that should be available at all communication and swallowing disorders centers and rehabilitation hospitals. These computer programs include a MossTalk word which is designed for treating Broca's aphasics. Intracranial Electrophysiology program is important software that can predict the type of impairment. It can help SLP/Ts diagnose the case precisely; therefore, determine the appropriate treatment he/she should be given. Mapping therapy and imaging techniques are also recommended when diagnosing aphasics. These include: Magnetic Resonance Imaging (MRI), Computed Tomography (CT), Functional Magnetic Resonance Imaging (FMRI), Positron Emission Tomography (PET), Near Infrared Spectroscopy (NIRS), Electroencephalography (EEG), Magnetoencephalography (MEG).

\section{Acknowledgment}

This work would not have been possible without guidance and help of prof. Kebbewho in a way or another contributed and extended his valuable assistance in the preparation and completion of this study.

\section{References}

'Abdul-Lațîf, N. (2005). Șu' ūbāt al-T'allum . 'Ammān: Maktabat al-Mujtam'a al-'Arabī Lil-Nashr . 'Alī, İ., \& Ḥasan, H. (2009). Șu'ūbāt al-T'allum Bayn al-Nazariyah Wa al-Tațbìq . 'Ammān: Dār al-Manāhij Lil-Nashr Wa al-Tawzì .

Abu-Ḥātim, S. (2005). Mahārāt al-Sama 'Wa al-Takhātub Wa al-Nuṭq al-Mubakkirah . 'Ammān : Dār 'Usāmah Lil-Nashr Wa al-Tawzì' .

Alexander, M., Fischette, M., \& Ficher, R. (1989). Crossed aphasias can be mirror image or anomalous. Case reports, review and hypothesis. Brain, 953-973.

al-Imām, M., \& al-Jawaldah, F. (2010). al-l'āqah al-'Aqliyah Wa Mahārāt al-Hayah Fı Dawa Nazariyat al-'Aql. 'Ammān: Dār al-Thaqāfah Lil-Nashr Wa al-Tawzì' .

al-Jawāldah, F. (2008). Fā'iliyat Barnāmaj Qā'im 'Alā Nazariyat al-'Aql Fì Tanmiyat Mahārāt Adāiya Ḥayātiyah Ladā al-Mu'āqīn 'Aqlīyan Fì al-'Urdun . Majallat Jāmi 'at 'Ammān Lil-Dirāsāt al-'Uliyā, 3-9.

Al-Senani, F. (2004a). 15\% die within 1 month of their stroke. Riadh: Okaz Newspaper.

Al-Senani, F. (2004b). 900 people die from Stroke every Year in Saudi Arabia. Riyadh: AlSharq AlAwsat Newspaper.

Anjarningsih, H., \& Bastiaanse, R. (2011). Verbs and time reference in Standard Indonesian agrammatic speech. Aphasiology, 1562-1578. http://dx.doi.org/10.1080/02687038.2011.626844.

Bakheit, A., Shaw, S., Carrington, S., \& Griffiths, S. (2007). The Rate and Extent of Improvement with Therapy from the Different Types of Aphasia in the First Year After Stroke. Clinical Rehabilitation, 941-949,9p, 1 chart, 1 diagram, 1 grap. 


\section{Ml Macrothink}

International Journal of English Language Education

ISSN 2325-0887

2013, Vol. 1, No. 2, Special Issue

Barber, N., Patterson, K., Ellis, K., \& Ralph, M. (2005). The relationship between phonological and morphological deficits in Broca's aphasia: Further evidence from errors in verb inflection. Brain\&Language, 278-287.

Barwood, C., Murdoch, B., Whelean, B., Lioyd, D., Riek, S., O'Sullivan, J., \& Wong, A. (2011). Modulation of N400 in chronic non-fluent aphasia using low frequency Repetitive Transcranial Magnetic Stimulation (rTMS). Brain\& Language, 125-135. http://dx.doi.org/10.1016/j.band1.2010.07.004

Bastiaanse, R., \& Thompson, C. (2003). Verb and Auxiliary Movement in Agrammatic Broca's Aphasia. . Brain\& Language, 286-286,1p.

Bastiaanse, R., \& VanZonneveld, R. (2004). Broca's Aphasia, Verbs and the Mental Lexicon. Brain \&Language, 198-202. http://dx.doi.org/10.1016/S0093-934X(03)00432-2.

Bastiaanse, R., \& VanZonneveld, R. (2005). Sentence Production with Verbs of Alternating Transitivity in Agrammatic Broca's Aphasia. Journal of Neurolinguistics, 57-66. http://dx.doi.org/ 10.1 016/j. jneuroling. 2004.11 .006

Bastiaanse, R., \& van-Zonneveld, R. (2006). Comprehension of passives in Broca's aphasia. Brain \& Language, 135-142.

Bastiaanse, R., Hurkmans, J., \& Links, P. (2006). The training of verb production in Broca's aphasia: A multiple-baseline across-behaviours study. Aphasiology, 298-311. http://dx.doi.org/10.1080/02687030500474922.

Beaton, A. (2011). Going for Broca? I wouldn't bet on it! . Behavioral and Brain Sciences, 212-213. (Document ID: 675767521).

Bendy, M., Hulbert, J., \& Thompson-Schill, S. (2007). Understanding words in context: The role of Broca's area in word comprehension. Brain Research, 101-114.

Benson, D. (1976). The Aphasias and Related Disturbances. In Baker, A.\&Baker,H.(Eds.), Clinical Neurology. New York: Harper and Row.

Bizzi, A., Nava, S., Ferre, F., Castelli, G., Aquino, D., Ciaraffa, F., \& Piacentini, S. (2012). Aphasia induced by gliomas growing in the ventrolateral frontal region: Assessment with diffusion MR tractography, functional MR imaging and neuropsychology. Cortex; A Journal Devoted To Study Of The Nervous System\& Behavior, 255-272.

Bonhoeffer, K. (1902). Zur Kenntnis der Ruckbildung Motorischer Aphasien (Towards an Understanding of the Evolution of Motor Aphasias). Mitteilungen aus den Grenzgebieten der Medizen und Chirugie , 203-224.

Boo, M., \& Rose, M. (2011). The efficacy of repetition, semantic, and gesture treatments for verb retrieval and use in Broca's aphasia. Aphasiology, 154-175. http://dx.doi.org/10.1080/02687031003743789 


\section{Ml Macrothink}

International Journal of English Language Education ISSN 2325-0887 2013, Vol. 1, No. 2, Special Issue

Bornkessel-Schlesewsky, I., Schlesewsky, M., \& Cramon, D. (2009). Word order and Broca's region: Evidence for a supra-syntactic perspective. Brain \& Language , 125-139. http://dx.doi.org/ 10. 1016/ j.bandl .2 009.09.004

Brammer, M. (2004). Correspondence: Brain Scam? Nature Neuroscience, 1015.

Bruel-Jungerman, E., Davis, S., \& Laroche, S. (2007). "Brain plasticity mechanisms and memory: A part of four". Neuroscientist , 492-505. http://dx.doi.org/10.1177/1073858 407302725.PMID 17901258.

Buckner, R., Kelley, W., \& Peterson, S. (2011). Frontal Cortex Contributions to Human Memory Formation. Nature Neuroscience, 311-314.

Burkhardt, P., Avrutin, S., Pinango, M., \& Ruigendijk, E. (2008). Slower-than-normal syntactic processing in agrammatic Broca's aphasia: Evidence from Dutch. Journal of Neurolinguistics, 120-137. http://dx.doi.org/1 0.1016/j.jneuroling.2006.10.004

Burns, M., \& Fahy, J. (2010). Broca's area: rethinking classical concepts from a neuroscience perspective. Topics In Stroke Rehabilitation, 401-410. http://dx.doi.org/10.1310/tsr1706-401.

Cantalupo, C., \& Hopkins, W. (2007). Asymmetric Broca's area in great apes. NIHPA, 505-509. HYPERLINK "http://en.wikipedia.org/wiki/Digital_object_identifier" lo "Digital object identifier" doi: HYPERLINK "http://dx.doi.org/10.1038\%2F35107134" 1 o.1 0 $38 / 35107134$.

Cappelletti, M., Butterworth, B., \& Kopelman, M. (2006). The Understanding of Quantifiers in Semantic Dementia: A Single-Case Study. Neurocase (Psychology Press), 136-145.

Cappelletti, M., Fregni, F., Shapiro, K., Pascual, A., \& Caramazza, A. (2008). Processing Nouns and Verbs in the Left Frontal Cortex: A Transcranial Magnetic Stimulation Study. . Journal Of Cognitive Neuroscience, 707-720.

Caramazza, A., Capasso, R., Capitani, E., \& Miceli, G. (2005). Patterns of comprehension performance in agrammatic Broca's aphasia: A test of the Trace Deletion Hypothesis. . Brain\&Language, 43-53. http://dx.doi.org/10.1016/jband1.2004.11.006.

Carlson, J., \& Donald, J. (2007). Psychology the science of behaviour. New York: Pearson Education Inc.

Cattaneo, Z., Devlin, J., Vecchi, T., \& Silvanto, J. (2009). Dissociable neural representations of grammatical gender in Broca's area investigated by the combination of satiation and TMS. Neuroimage, 700-704. http://dx.doi.org/10.1016/j.neuroimage.2009.04.097.

Cattaneo, Z., Pisoni, A., \& Papagno, C. (2011). Transcranial direct current stimulation over Broca's region improves phonemic and semantic fluency in healthy individuals. . Neuroscience, 64-70. http://dx.doi.org/10. 1 016/j.neuroscience.2011.03.058

Centeno, J. (2007). Canonical features in the inflectional morphology of Spanish-speaking individuals with agrammatic speech. Advances In Speech Language Pathology, 162-172. 


\section{Macrothink}

International Journal of English Language Education

ISSN 2325-0887

2013, Vol. 1, No. 2, Special Issue

Clerget, E., Poncin, W., Fadiga, L., \& Olivier, E. (2012). Role of Broca's Area in Implicit Motor Skill Learning: Evidence from Continuous Theta-burst Magnetic Stimulation. . Journal of Cognitive Neuroscience, 80-92.

Columbia Electronic Encyclopedia,6th Edition,1. (2011). Paul Broca. Columbia: Columbia University Press.

Commondoor, R., Eisenhut, M., \& Fowler, C. (2009). Transient Broca's Aphasia as Feature of an Extradural Abscess. Pediatr Neurol, 50-53. http://dx.doi.org/10.1016/j.pediatrneurol.2008.06.018.

Crowe, T. (1997). Applications of Counseling in Speech-Language Pathology and Audiology. New Jersey: Williams \&Wilkins.

Crystal, D. (1980). Introduction to Language Pathology. London: Edward Arnold(Publishers)Ltd.

Darley, F. (1964). Diagnosis and Appraisal of Communicative Disorders. New Jersey: Prentice-Hall Inc.

Davis, C., Kleinman, J., Newhart, M., Gingis, L., Pawlak, M., \& Hillis, A. (2008). Speech and language functions that require a functioning Broca's area. Brain and Language, 50-85.

Decety, J., \& Jackson, P. (2004). The functional architecture of human empathy. Behavioral and Cognitive Neuroscience of Human Empathy, 71-100. (Document ID: 1153995521).

Demonet, C., Price, R., \& Frackowiak, J. (2011). A PET study of cognitive strategies in normal subjects during language tasks: Influence of phonetic ambiguity and sequence processing on phoneme monitoring. Brain, 671-82 (Document ID: 24034301).

den Ouden, D. d., Hoogduin, H., Stowe, L., \& Bastiaanse, R. (2008). Neural correlates of Dutch Verb Second in speech production. Brain \& Language, 122-131. http://dx.doi.org/10.1016/j.bandl.2007.05.001.

de Vries, M., Barth, A., Maiworm, S., Knecht, S., Zwitserlood, P., \& Floel, A. (2010). Electrical Stimulation of Brocas Area Enhances Implicit Learning of an Artificial Grammar. Journal of Cognitive Neuroscience, 2427-2436.

Dronkers, N., Plaisant, O., Iba-Zizen, M., \& Cabanis, E. (2011). Paul Broca's historic cases: high resolution MR imaging of the brains of Leborgne and Lelong. Brain, 1432-1441. (Document ID: 1264673041).

Duman, T., Altinok, N., Ozgirgin, N., \& Batiaanse, R. (2011). Sentence comprehension in Turkish Broca's aphasia: An integration problem. Aphasiology, 908-926. http://dx.doi.org/10.1080/02687038.2010.550629.

Dworkin, J. (1991). Motor Speech Disorders: A Treatment Gude. New York: Mosby Year Book Inc. 


\section{Macrothink}

International Journal of English Language Education ISSN 2325-0887 2013, Vol. 1, No. 2, Special Issue

Eiling, Y., Blumstein, S., \& Sedivy, J. (2008). Lexical-Semantic Activation in Broca's and Wernicke's Aphasia: Evidence from Eye Movements. Journal of Cognitive Neuroscience, 592-612.

Eisenson, J. (1972). Aphasia in Children. New York: Harper\&Row.

Eisenson, J. (1973). Adult Aphasia: Assessment and Treatment . New Jersey: Englewood Cliffs.

Engelter, S., Gostynski, M., Papa, S., Freie, M., Born, C., Ajdacic-Gross, V., ...Lyrer, P. (2006). Epidemiology of Aphasia Attributable to First Ischemic Stroke: Incidence, Severity, Fluency, Etiology, and Thrombolysis. Stroke, 1379-84.

Faroqi-Shah, Y., \& Thompson, C. (2003). ). Effect of lexical cues on the production of active and passive sentences in Broca's and Wernicke's aphasia. Brain \& Language, 409-409,1p. http://dx.doi.org/10. 1016/ S0 093-934X(02)00586-2

Fiez, J. (2011). Functional anatomy of lexical processing: PET activation and performance studies. Washington University, United States -- Missouri, 2-8 (Publication No. AAT 9317387).

Ford, A., McGregor, K., Case, K., Crosson, B., \& White, K. (2010). Structural connectivity of Broca's area and medial frontal cortex. Neuroimage, 1230-1237. http://dx.doi.org/10.1016/j.neuroimage.2010.05.018.

Friederici, J., \& Angela, D. (2011). Autonomy of syntactic processing and the role of Broca's area. Behavioral and Brain Sciences, 634-635 (Document ID: 23064799).

Gentilucci, M., Bernardis, P., Crisi, G., \& Volta, R. (2006). Repetitive Transcranial Magnetic Stimulation of Broca's Area Affects Verbal Responses to Gesture Observation. Journal of Cognitive Neuroscience, 1059-74.

Geschwind, N. (1965a). Disconnexion Syndromes in Animals and Man. Brain, 237-294.

Geschwind, N. (1965b). Disconnexion Syndromes in Animals and Man . Brain, 585-644.

BIBLIOGRAPHY $\backslash 11033$ Geschwind, N. (1971). Current Concepts: Aphasia. New England Journal of Medicine, 284, 654-6.

Goodglass, H. (1968). Studies on the Grammar of Aphasics. In Koplin, J.H.(Ed.), Developments in Applied Psycholinguistic Research. New York: Macmillan.

Goodglass, H. (2000). The Assessment of Aphasia and Related Disorders. Philadelphia: Williams \& Wilkins.

Gove, P., \& Webster, M. (1981). Webster's third new international dictionary of the english language, unabridged. Springfield : Merriam-Webster, cop.

Grande, M., Meffert, E., Huber, W., Amunts, K., \& Heim, S. (2011). Word frequency effects in the left IFG in dyslexic and normally reading children during picture naming and reading. Neurimage, 1212-20. http://dx.doi.org/10.1016/j.neuroimage.2011.05.033 
Grodzinsky, Y. (2000). The neurology of syntax: Language use without Broca's area. Behavioral and Brain Sciences, 1-21 (Document ID: 54327418).

Hallahan, D., \& Kauffman, J. (1994). Exceptional Children: Introduction to Special Education. New Jersey: Prentice-Hall, Inc.England Cliffs.

Halpern, H., Darley, F., \& Brown, J. (1973). Differential Language and Neurologic Charactersitics in Neurologic Involvement. J.Speech Hear.Disord, 162-73.

Harciarek, M., \& Kertesz, A. (2011). "Primary progressive aphasias and their contribution to the contemporary knowledge about the brain-language relationship". Neuropsychol Rev, 271-87. http://dx.doi.org/10.1007/s11065-011-9175-9.PMC 3158975. PMID 21809067.

Harris, L., Olson, A., \& Humphreys, G. (2012). Rehabilitation of past tense verb production and non-canonical sentence production in left inferior frontal non-fluent aphasia. Aphasiology, 143-161.http://dx.doi.org/10.1080/02687038.2011.624166.

Havik, E., \& Bastiaanse, R. (2004). Omission of definite and indefinite articles in the spontaneous speech of agrammatic speakers with Broca's aphasia. Aphasiology, 1093-1102. http://dx.doi.org/10.1080/02687030444000 543

Head, H. (1926). Aphasia and Kindred Disorders of Speech. New York: Macmillan.

Hedge, M. (1998a). A Coursebook on Aphasia and Other Neurogenic Language Disorders. NY: Thomson Delmar Learning.

Hedge, M. (2001a). Hegde's Pocketguide to Assessment in Speech-Language Pathology. NY: Delmar Learning.

Hedge, M. (2001b). Hegdge's Pocketguide to Treatment in Speech-Language Pathology. Clifton Park. NY: Delmar Learning.

BIBLIOGRAPHY $\backslash 11033$ Heim, S., Eickhoff, S., Friederici, A., \& Amunts, K. (2011b). Left cytoarchitectonic area 44 supports selection in the mental lexicon during language production. Brain Structure and Function, 441-56. (Document ID: 1852562861). http://dx.doi.org/10.1007/s00429-009-0213-9.

Heim, S., Eickhoff, S., Ischebeck, A., Supp, G., \& Amunts, K. (2011a). Modality-independent involvement of the left BA 44 during lexical decision making. Brain Structure and Function, 95-106. (Document ID: 1484067881).

Hellyer, P. (2012). Searching for Cyrillic items in the catalogues of the British Library: guidelines and transliteration tables. British Library, 1.

Helm-Estabrooks, N., \& Ramsberger, G. (1986). Treatment of Agrammatism in Long-Term Broca's Area. British Journal of Disorders of Communication, 39-45.

Herman, G. (2009). Fundamentals of computerized tomography: Image reconstruction from projection. Springer, 12-21. 


\section{Al Macrothink}

International Journal of English Language Education

ISSN 2325-0887

2013, Vol. 1, No. 2, Special Issue

Hickok, G., Costanzo, M., Capasso, R., \& Miceli, G. (2011). The role of Broca's area in speech perception: Evidence from aphasia revisited. Brain\&Lnaguage, 214-220. http://dx.doi.org/10.1016/j.bandl.2011.08.001.

Howard-Barr, E., Rienzo, B., Pigg, R., \& James, D. (2011). Teacher Beliefs, Professional Preparation, and Practices Regarding Exceptional Students and Sexuality Education. The Journal of School Health, 18-27.

Howes, D. (1964). Application of the Word Frequency Concept to Aphasia. In: A.V.S. De Reuck and M.O'Connor(Eds.), Disorders of Language. London: Churchill Ltd.

Ingalls, R. (1945). Mental Retardation: The Changing Outlook. New Hersey: John Wiley\& Sons Inc.

International, Ș. (1997). The Qur'an: Arabic Text with Corresponding English Meanings. London: Abul Qasim Publishing House.

Jakobson, R. (1963). Towards a Linguistic Typology of Aphasic Impairment. In De Reuck,AVS,O'Connor,M.(Eds.), Disorders of alanguage. London: Churchill.

Jianu, D., Muresanu, D., Bajenaru, O., Popescu, B., Deme, S., Moessier, H., \& Petrica, L. (2010). Cerebrolysin adjuvant treatment in Broca's aphasics following first acute ischemic stroke of the left middle cerebral artery. Journal of Medicine\&Life, 297-307.

Jonkers, R., \& de-Bruin, A. (2009). Tense processing in Broca's and Wernicke's aphasia. . Aphasiology, 1252-65. http://dx.doi.org/10.1080/02687030802289192.

Jordan, L. (1989a). Family or Volunteer? Therapy Weekly, 16., L., \& Kaiser, W. (1996). Aphasia-A Social Approach. Atlanta: Prentice Hall Inc.

Judas, M., \& Cepanec, M. (2007). Adult structure and development of the human fronto-opercular cerebral cortex (Broca's region).Clinical Linguistics \&Phonetics, 975-989. http://dx.doi.org/10.1080/0 2699200701617175.

Justus, T., Larsen, J., Yang, J., Davies, P., Dronkers, N., \& Swick, D. (2011). The role of Broca's area in regular past-tense morphology: An event-related potential study. Neuropsychologia, 1-18. http://dx.doi.org/10.1016/j.neuropsychologia.2010.10.027.

Kang, E., Kim, Y., Sohn, H., Gohen, L., \& Paik, N. (2011). Improved picture naming in aphasia patients treated with cathodal tDCS to inhibit the right Broca's homologue area. . Restorative Neurology\&Neuroscience, 141-152.

Kauhanen, M., Korpelainen, J., Hiltunen, P., Maata, R., Mononen, H., Brusin, E., . . Myllyla, V. (2000). Aphasia, Depression, and Non-Verbal Cognitive Impairment in Ischaemic Stroke. Cerebrovascular Disease, 455-61.

Keller, S., Croq, T., Foundas, A., Amunts, K., \& Roberts, N. (2009). Broca's area: Nomenclature, anatomy, typology and asymmetry. Brain\&Language, 29-48. http://dx.doi.org/10.1016/j.band1.2008.11.005. 
Keller, S., Highley, J., Gracia-Finana, M., Sluming, V., Razaie, R., \& Roberts, N. (2007). Sulcal variability, stereological measurement and asymmetry of Broca's area on MR images. Journal of Anatomy, 534-555. http://dx.doi.org/10.1111/j.1469-7580.2007.00793.x.

Keller, S., Roberts, N., \& Hopkins, W. (2009). A Comparative Magnetic Resonance Imaging Study of the Anatomy, Variability, and Asymmetry of Broca's Area in the Human and Chimpanzee Brain. Journal of Neuroscience, 14607-16. http://dx.doi.org/10.1523/JNEUROSCI.2892-09.2009.

Khașawnah, M., Abu-Sha'īrah, K., \& Ghubārī, T. (2010). al-Tarbiyah al-Khāșșah Bayn al-Tawjīhāt al-Nazariyah Wa al-Tațīqiyah . 'Ammān: Maktabat al-Mujtama' al-'Arabī Lil-Nashr Wa al-Tawzī' .

Kolb, B., \& Whishaw, I. (2003). Fundamentals of human neuropsychology. New York: Worth. Press.

Kotz, S., D'Ausilio, A., Raettig, T., Begliomini, C., Craighero, L., Fabbri-Destro, M., \& Fadiga, L. (2010). Lexicality drives audio-motor transformations in Broca's area. Brain\&Language, 3-11.http://dx.doi.org/1 0.1016/j.bandl.2009.07.008.

Lazar, R., \& Mohr, J. (2011). Revisiting the Contributions of Paul Broca to the Study of Aphasia. Neuropsychology Review, 236-239. http://dx.doi.org/10.1007/s11065-011-9176-8.

Lenneberg, E. (1973). The Neurology of Language. Daedalus, 115-33.

Links, P., Hurkmans, J., \& Bastiaanse, R. (2010). Training verb and sentence production in $\begin{array}{llll}\text { agrammatic } \quad \text { Broca's } & \text { aphasia. } & \text { Aphasiology, } 25 .\end{array}$ http://dx.doi.org/10.1080/02687030903437666.

Luria, A. (1964). Factors and Forms of Aphasia. In A.V. De Reuk\& M.O'Conner(Eds.), Ciba Foundation Symbosium in Disorders of Language. Boston: Little Brown.

Mahdavi, A., Saberi, H., Rezvanizadeh, A., Lavasani, A., Nilipour, R., Oghabian, M., \& Ghanaati, H. (2008). Functional Imaging of Broca's Area in Native Persian Speakers: An fMRI Study. Iranian Journal of Radiology, 215-220.

Makris, N., \& Pandya, D. (2009). "The extreme capsule in humans and rethinking of the language circuitry". Brain Struct Funct, 343-58. http://dx.doi.org/10.1007/s00429-008-0199-8. PMID 19104833.

Mansur, R., Penha, D., \& Adda, J. (2007). Verbal and Non-Verbal Deficits of Inhiibition: Evidence for Lateralization in Crosses Aphasia. Presented by Helen Owen(2007) for B.S.c Cognitive Neuroscience. Bangor: University of Wales.

Marie, P. (1906). The Third Left Frontal Convolution Plays No Special Role in the Function of Language. Semaine Medicale, 241-247.

Marková, J., \& Cséfalvay, Z. (2010). Morphological-syntactic deficits in the production of Slovak-speaking aphasic patients. Aphasiology, 1197-1222. http://dx.doi.org/10.1080/02687030903422452. 
Maton, A., Jean, H., Charles, W., Susan, J., Maryanna, Q., David, L., \& Wright, J. (1993). Human Biology and Health. Englewood Cliffs, 132-144. HYPERLINK "http://en.wikipedia.org/wiki/International_Standard_Book_Number" lo "International Standard Book Number" - ISBN "http://en.wikipedia.org/wiki/Special:BookSources/0-13-981176-1" "Special:BookSources/0-13-981176-1" 0-13-981176-1 .

Mesulam, M. (2001). "Primary progressive aphasia". Ann. Neurol, 425-32. http://dx.doi.org/10.1002/ana.91. PMID 11310619.

Michiru, M. (2011). Is Broca's Area Crucial for Imitation?. Cerebral Cortex, 563-70. (Document ID: 862824981).

Miḷ̣m, S. (2002). Șu'ūbāt al-T'allum 2002. 'Ammān : Dār al-Masīrah Lil-Nashr Wa al-Tawzī'.

Molnar-Szakacs, I. (2011). The human mirror neuron system and nonverbal social communication: Action observation, imitation and gesture perception. University of California, Los Angeles, United States -- California, 2-7. (Publication No. AAT 3202820).

Musso, M., Moro, A., Glauche, V., Rijintjes, M., Reichenbach, J., Buchel, C., \& Weiller, C. (2003). Broca's area and the language instinct. . Nature Neuroscience, 774-774,1p.

BIBLIOGRAPHY $\backslash 11033$ Musso, M., Weiller, C., Kiebel, S., Muller, S., Bulau, P., \& Rijntjes, M. (2011). Training-induced brain plasticity in aplasia. Brain, 1781 -90. (Document ID: 45047975).

Nakano, H., \& Blumstein, S. (2004). Deficits in thematic integration processes in Broca's and Wernicke's aphasia. . Brain \& Language, 96-96, $1 \mathrm{p}$. http://dx.doi.org/10.1016/S0093-934X(03)00280-3.

Novick, J. (2005). Cognitive control and the role of Broca's area in sentence processing. University of Pennsylvania Journal , United States., 2-9.http://dx.doi.org/10.1016/j.jneuroling.2007.05.001.

Osterweil, N. (2011). "Medical Research Spending Doubled Over Past Decade. MedPage Today, 2-6.

Pacher, P., Batkai, S., \& Kunos, G. (2006). "The Endocannabinoid System as an Emerging $\begin{array}{llll}\text { Target of Pharmacotherapy. } & \text { Pharmacol }\end{array}$ http://dx.doi.org/10.1124/pr.58.3.3.PMC2241751.PMID16968947.

Pang, E., Wang, F., Malone, M., Kadis, D., \& Donner, E. (2011). Localization of Broca's area using verb generation tasks in the MEG: Validation against fMRI. . Neuroscience Letters, 215-219. http://dx.doi.org/10.1016/j.neulet.2010.12.055.

Parr, S. (2003). Aphasia Inside Out: Reflection on Communication Disability. New York: Open University Press. 


\section{Al Macrothink}

International Journal of English Language Education ISSN 2325-0887

2013, Vol. 1, No. 2, Special Issue

Peristeri, E., \& Tsapkini, K. (2011). A comparison of the BAT and BDAE-SF batteries in determining the linguistic ability in Greek-speaking patients with Broca's aphasia. . Clinical Linguistics \& Phonetics, 464-479. http://dx.doi.org/10.3109/02699206.2011.560991.

Philips, B., \& Ruscello, D. (1998). Differential Diagnosis in Speech-Language Pathology,H.A.\&Marquardt,T.P.(1981). Appraisal and Diagnosis. London: Prentice-Hall, Inc.

Platz, T., Naeser, M., Martin, P., Treglia, E., Ho, M., Kaplan, E., \& Pascual-Leone, A. (2010). Research with rTMS in the treatment of aphasia. Restorative Neurology\&Neuroscience, 511-529. http://dx.doi.org/10. 323 3/RNN-2010-0559.

Ragalsky, C., \& Hickok, G. (2008). The Role of Broca's Area in Sentence Comprehension. Brain, 2-8.

Rivers, T., Spunt, D., \& Berry, G. (1933). Observations on Attempts to Produce Acute Disseminated Encephalomyelitis in Monkeys . Journal of Experimental Medicine , 39-53.

Rockey, D. (1980). Speeech Disorder in Nineteenth Century British. London: Croom Helm Ltd.

Roth, J., \& Worthington, C. (2005). Treatment Resource Manual for Speech-Language Pathology. New York: Delmar Learning.

Rothstein, J. (2005). The Rehabilitation Specialist's Handbook. Philadelphia: F.A. Davis Company.

Ruigendijk, E., \& Baauw, S. (2007). Syntactic and pragmatic aspects of determiner and pronoun production in Dutch agrammatic Broca's aphasia. Aphasiology, 535-547. http://dx.doi.org/10.108 0/02 687030701191911.

Salomon, E. (1914). Motorische Aphasie Mit Agrammatismus und Sensorisch-Agrammatischen Storungen (Motor Aphasia with Agrammatism and Sensory-Agrammatic Disorders. Monatsschrift fur Psychiatrie Und Neurologie, 181-275.

Schlaug, G., Marchina, S., \& Norton, A. (2008). From Singing to Speaking: Why Singing May Lead to Recovery of Expressive Language Function in Pattern with Broca's Aphasia. Music Perception, 315-323.

Schlaug, G., Marchina, S., \& Wan, C. (2011). The Use of Non-invasive Brain Stimulation Techniques to Facilitate Recovery from Post-stroke Aphasia. Neuropsychology Review, 288-301. http://dx.doi.org/10.1 00 7/s11065-011-9181-y.

Scott, R., \& Wilshire, C. (2010). Lexical competition for production in a case of nonfluent aphasia: Converging evidence from four different tasks. Cognitive Neuropsychology, 505-538. http://dx.doi.org/ 10.1080/02643294.2011.598853.

Semenza, C., Pellegrin, S., Battel, I., Garzon, M., Meneghello, F., \& Chiarelli, V. (2011). Compounds in different aphasia categories: A study on picture naming. Journal of Clinical \& 
http://dx.doi.org/10.1080/13803395.2011.603691.

Shipley, K., \& Mcafee, J. (2004). Assessment in Speech-Langauge Pathology. A Resource Manual. Florence: Delmar Learning.

Shuell, H., Jenking, J., \& Jimenezpabon, E. (1964). Aphasia in Adults. New York: Harper and Row.

Simmons, M. (2001). Social Approaches to Aphasia Intervention. In R.Chapey (Ed.), Language Intervention Strategies in Aphasia and Related Neurogenic Communication Disorders. Philadelphia: Lippincott Williams \& Wilkins.

Singla, S., Nehru, R., Singhla, G., Sharma, J., Khanam, F., \& Agrawal, S. (2007). Separate and dissociable lexical phonological and lexical semantic processing systems in naming: Evidence from a single case study of Broca's aphasia. Annals of Indian Academy of Neurology, 1050-1050,1p.

Skipper, J., Goldin-Meadow, S., Nasbaum, H., \& Small, S. (2007). Speech-associated gestures, Broca's area, and the human mirror system. . Brain\&Language , 260-277. (Publication No. AAT 3252 247).

Smith, A. (1971). Objective Indices of Severity of Chronic Aphasia in Stroke Patients. J.Speech Hear.Disord, 167-207.

Spreen, O., \& Risser, A. (2003). Assessment of Aphasia. Oxford: University Press.

Squire, L., Stark, C., \& Clark, R. (2004). The medial temporal lobe. Annu. Rev. Neuroscience, 279-306.

Stark, J. (2010). Long-Term Analysis of Chronic Broca's Aphasia: An Illustrative Single Case. . Seminars in Speech\& Language, 5-20.

Starkweather, C. (1983). Speech and Language: Priciples and Processes of Behaviour Change. London: Prentice-Hall Inc.

Stedman, J. (1972). Medical Dictionate. Baltmore: Williams \& Wilkins.

Taglialatela, J., Russell, J., Schaeffer, J., \& Hopkins, W. (2011). Chimpanzee Vocal Signaling Points to a Multimodal Origin of Human Language. Plos ONE, 1-7. http://dx.doi.org/10.1371/journal.pone.0018852.

Tanner, D. (2003). Exploring Communication Disorders: A 21st Century Introduction Through Literature and Media. New York: Pearson Education Inc.

Terao, Y., Ugawa, Y., Yamamoto, T., Sakurai, Y., Masumoto, T., \& Tsuji, S. (2007). Primary face motor area as the motor representation of articulation. Journal Of Neurology, 442-447. http://dx.doi.org/10.1007/s00415-006-0385-7.

Thomsen, T., Shaffer, R., \& Setnik, G. (2006). Videos in clinical medicine. Nasogastric intubation. N Engl J Med, 17. http://dx.doi.org/10.1056/NEJMvcm050183.PMID16641390. 


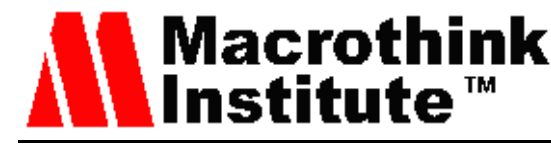

International Journal of English Language Education ISSN 2325-0887

2013, Vol. 1, No. 2, Special Issue

Tsapkini, K., Vivas, A., \& Triarhou, L. (2008). 'Does Broca's area exist?': Christofredo Jakob's 1906 response to Pierre Marie's holistic stance. Brain\&Language, 211-219. http://dx.doi.org/10.10 16/j.b and 1.20 07.07.124.

Tyler, L., Marslen-Wilson, W., Randall, B., Wright, P., Devereux, B., Zhuang, J., \& Stamatakis, E. (2011). Left inferior frontal cortex and syntax: function, structure and behaviour in patients with left hemisphere damage. Brain: A Journal of Neurology, 415-431.

Vaden Jr, K., Piquado, T., \& Hickok, G. (2011). Sublexical Properties of Spoken Words Modulate Activity in Broca's Area but Not Superior Temporal Cortex: Implications for Models of Speech Recognition. Journal of Cognitive Neuroscience, 2365-74.

van Lieshout, P., Bose, A., Square, P., \& Steele, C. (2007). Speech motor control in fluent and dysfluent speech production of an individual with apraxia of speech and Broca's aphasia. Clinical Linguistics \& Phonetics, 159-188. http://dx.doi.org/10.1080/02699200600812331.

Venkataraja-Aithal, U., Veena, K., James, G., \& Rajashekhar, B. (2009). Morphosyntactic deficits in Malayalam-speaking Broca's aphasics. . Asia Pacific Journal of Speech, Language \&Hearing, 303-314.

Wassenaar, M., \& Hagoort, P. (2005). Word-category violations in patients with Broca's aphasia: An ERP study. . Brain \& Language, 117-137. http://dx.doi.org/10.1016/j.bandl.2004.05.011.

Wassenaar, M., \& Hagoort, P. (2007). Thematic role assignment in patients with Broca's aphasia: Sentence-picture matching electrified. Neuropsychologia, 716-740. http://dx.doi.org/10.1016/j. neuro psych ologia.2006.08.016.

Wassenaar, M., Brown, C., \& Hagoort, P. (2004). ERP Effects of Subject-Verb Agreement Violations in Patients with Broca's Aphasia. Journal of Cognitive Neuroscience, 553-576. http://dx.doi.org/10.1162/089 892904323057290.

Whitaker, H. (1971). On the Presentation of Language in the Human Brain: Problems in the Neurology of Language and the Linguistic Analysis of Aphasia. Washington, DC: Linguistic Research Inc.

Whitaker, H., \& Whitaker, H. (1976). Studies in Neurolinguistics. New York: Academic Press.

Yin, R. (1981). The Case Study Crisis: Some Answers. Administrative Science Quarterly, 58-65.

BIBLIOGRAPHY $\backslash 11033$ Zhang, M. (2011). Modulation of the cannabinoid CB1 and CB2 receptor activation in central nervous system disorders. Temple University, United States -Pennsylvania, 3-11. (Publication No. AAT 3300388).

Zhang, F., Tian, Y., Wei, L., Yu, F., Chen, H., \& Wang, K. (2011). More vulnerable processing of shengmu than yunmu in a Chinese Broca's aphasic. Journal of Neurolinguistics , 374-382. http://dx.doi.org/10.1016/j.jneuroling.2010.12.004. 
Glossary

ALS-LC (American Library Association- Library of Congress) $=$ is a set of standards for Romanization, or the representation of text in other writing systems using the Latin alphabet (Hellyer, 2012, P.1)

ATL (Anterior Temporal Lobe) $=$ It is the front part of the region of the cerebral cortex that is located beneath the Sylvian fissure on both cerebral hemispheres of the mammalian brain\} (Squire et al., 2004, PP.279-306)

BA $($ Broca's Area $)=$ It is one of the main areas of the cerebral cortex (a region of the hominid brain) responsible for producing language (Cantalupo\& Hopkins, 2007, P. 505)

C1, 2 (Cannabinoid one, two) = They are a class of diverse chemical compounds that activate cannabinoid receptors. They occur naturally in the nervous and immune systems of animals. (Pacher et al., 2006, Pp. 389-462.

CAD $($ Crossed Aphasia in Dextral) $=$ It refers to a language (symbolic communication with words) disorder resulting from a unilateral right hemispheric lesion in dextral (right-handers) (Alexander et al., 1989, Pp.953-973).

CAT (Computerized Axial Tomography) = It is a medical imaging procedure that utilizes computer-processed X-rays to produce tomographic images or 'slices' of specific areas of the body. Computerized tomography is more commonly known by its abbreviated names, CT scan or CAT scan (Herman, 2009, PP. 1-3).

CVA (Cerebral Vascular Accidents) = It is another name for a stroke. It is damage to the brain caused by a disruption of the blood supply to a part of the brain. This disruption of blood supply can be caused by blockage or a hemorrhage (Sims \&Muyderman, 2009, P. 83).

DCT (Discourse Competition Test) $=$ It is a technique used to elicit data in sociolinguistic research, and effects of systematic modification to its situational prompt on subject response (Barghese\& Billmyer, 1996, P1).

CNS (Central Nervous System) $=$ is the part of the nervous system that integrates the information that it receives from, and coordinates the activity of, all parts of the bodies of bilaterian animals. CNS is made up of spinal cord and brain (Maton et al., 1993, Pp. 132-144).

DT-MRI (Diffusing Tensor Magnetic Resonance Imaging) = is a technology that measures the random motion of hydrogen atoms within water molecules in all three dimensions, in biological tissues, in vivo and non-invasively (Le Bihan\& Breton, 1985, Pp. 1109-1112)

EAE (Experimental Autoimmune Encephalomyelitis) $=$ It is an animal model of brain inflammation. It is an excellent model of post-vaccinal encephalitis and a useful model of many aspects of multiple sclerosis (Rivers et al., 1933, Pp.39-53).

EmC (Extreme Capsule) $=$ (also known as the capsula extrema). It is a tract of long association fiber, which is a type of nerve fiber that provides bidirectional communication 
between such areas as the claustrum and the insular cortex, and the inferior frontal gyrus( BA) and the middle-posterior portion of the superior temporal gyrus(WA) (Makris \&Pandya, 2009, P. 351).

ERRC (External Research Review Committee) $=$ The center which is responsible for researches undertaken at King Fahd Medical City.

FMRI (Functional Magnetic Resonance Imaging) = It is an MRI procedure that measures brain activity by detecting associated changes in blood flow. This imaging technique can be used to produce activation maps showing which parts of the brain are involved in a particular mental process. (Brammer, 2004, 1095).

IFG (Inferior Frontal Gyre) = It is a gyrus of the frontal lobe. It includes an opercular section, orbital section and triangular section (Nolte, 2002, P. 526).

IRBs (Institutional Review Boards) = It is a committee that has been formally designated to approve, monitor, and review researches, notably biomedical and behavioral ones (Institutional Review Board Guidebook, 2012, P.9).

KFMC (King Fahd Medical City) $=$ The place where the current study takes place. http://www.kfmc.med.sa.

KSA (Kingdom of Saudi Arabia).

LAC (Left Anterior Cortex) = It is the frontal part of the cingulate cortex, that resembles a "collar" form around the corpus callosum (Decety \&Jackson, 2004, 71-100).

LH (Left Hemisphere) = Unlike the right side of the brain which is responsible for emotions, love, and sentiment, the left side of the brain is the seat of language and processes in a logical and sequential order (Western et al., 2006, Pp.107-108).

LIFG (Left Inferior Frontal Gyrus) = Inferior frontal gyrus consists of two sub-gyri: Left inferior frontal gyrus (LIFG) and right inferior frontal gyrus (RIFG). LIFG plays a role in in re-analyzing facial misinterpretation (Novick, 2005, P. 18).

MCA (Middle Cerebral Artery) = It is the most common site of stroke. It is also one of three major paired arteries that supply blood to the cerebrum (Moore \& Dalley, 1999, P. 14).

MCA/OR (Middle Cerebral Artery Occlusion/ Reperfusion) = An occlusion in MCA refers to a sudden onset of focal neurologic deficit resulting from brain infarction or ischemia (Zhang, 2011, PP.3-11).

MMA (Montpellier Medical Association) = It is a place where French neurologists used to meet weekly and discuss medical affairs (al-Faramāwīi, 2009, 101-106).

MRA (Magnetic Resonance Angiogram) = It is a group of techniques based on magnetic resonance imaging (MRI) to image blood vessels. In many cases MRA can provide information that can't be obtained from an X-ray, ultrasound, or computed tomography (CT) scan. (Cukar et al., 2009, Pp.1533-1539). 
MRI (Magnetic Resonance Imaging) = It is a test that uses a magnetic field and pulses of radio wave energy to make pictures of organs and structures inside the body (Sheil, 2012, P. $3)$.

NAAA (National Aphasia Association Award) = Awards given by National Aphasia Association which is a nonprofit organization that promotes public education, research, rehabilitation and support services to assist people with aphasia and their families (http://www.aphasia.org/).

NG (Nasogastric) = It is a medical process involving the insertion of a plastic tube (nasogastric tube or NG tube) through the nose, past the throat, and down into the stomach. By inserting a nasogastric tube, you are gaining access to the stomach and its contents (Thomsen et al., 2006, P. 354).

$\mathrm{NIH}$ (National Institute of Health) = It is an agency of the United States Department of Health and Human Services and is the primary agency of the United States government responsible for biomedical and health-related research (Osterweil, 2011, Pp.2-5).

PPA (Primary Progressive Aphasia) = It is a rare disorder where people slowly lose their ability to talk, read, write, and comprehend what they hear in conversation over a period of time (Mesulam, 2001, Pp. 2-5).

RH (Right Hemisphere) = It is one of the two regions of the vertebrate brain that are delineated by the median plane, (medial longitudinal fissure). It has an outer layer of grey matter called the cerebral cortex that is supported by an inner layer of white matter. Unlike the left hemisphere which is responsible for language, the right hemisphere controls cognitive functioning or thinking skills (Western et al., 2006, P.107).

SLPs (Speech-Language Pathologists) = They are specialized in communication disorders as well as swallowing disorders. They are also called Speech Therapists (Block et al., 1993, P. 23)

TBI (Traumatic Brain Injury) $=$ It occurs when an external force traumatically injures the brain. TBI can result when the head suddenly and violently hits an object, or when an object pierces the skull and enters brain tissue (Rehman et al., 2008, Pp.1-7).

UHIR (University of Helsinki's Illuminate Research) = A research center specialized in conducting research of different types of aphasia (Schlaug et al., 2008, Pp. 2-8).

WA $($ Wernicke's area) $=$ It is a region of the brain that contains motor neurons involved in the comprehension of speech. It is named after Carl Wernicke's, a German neurologist who first identified it in 1874 (Wernicke, 1995, P. 87).

\section{Copyright Disclaimer}

Copyright reserved by the author(s).

This article is an open-access article distributed under the terms and conditions of the Creative Commons Attribution license (http://creativecommons.org/licenses/by/3.0/). 